\title{
222-S Laboratory Fume Hood Testing Study
}

\author{
B.H. Ruelas \\ CH2M HILL Hanford Group, Inc. \\ Richland, WA 99352 \\ U.S. Department of Energy Contract DE-AC27-99RL14047
EDT/ECN: DRF UC:
Cost Center: 7S900 Charge Code: 502052
B\&R Code: Total Pages: 54

Key Words: 222-S Laboratory, fume hood, testing, study, plan, face velocity, profile, room, hood, arm port, open face, airflow, safe operation, containment, smoke (visualization), vapors, turbulence, results, evaluations, analytical equipment, as-used, ANSV/ASHRAE 110-1995, recommendations, conclusions, Maintenance Procedure 2S99003, properties, characteristics, sash, readings

Abstract: The 222-S Laboratory contains 155 active fume hoods that are used to support analytical work with radioactive and/or toxic materials. The performance of a fume hood was brought into question after employees detected odors in the work area while mixing chemicals within the subject fume hood.

Following the event, testing of the fume hood was conducted to assess the performance of the fume hood. Based on observations from the testing, it was deemed appropriate to conduct performance evaluations of other fume hoods within the laboratory.

TRADEMARK DISCLAIMER. Reference herein to any specific commercial product, process, or service by trade name, trademark, manufacturer, or otherwise, does not necessarily constitute or imply its endorsement, recommendation, or favoring by the United States Government or any agency thereof or its contractors or subcontractors.

Printed in the United States of America. To obtain copies of this document, contact: Document Control Services, P.O. Box 950, Mallstop H6-08, Richland WA 99352, Phone (509) 372-2420; Fax (509) 376-4989.

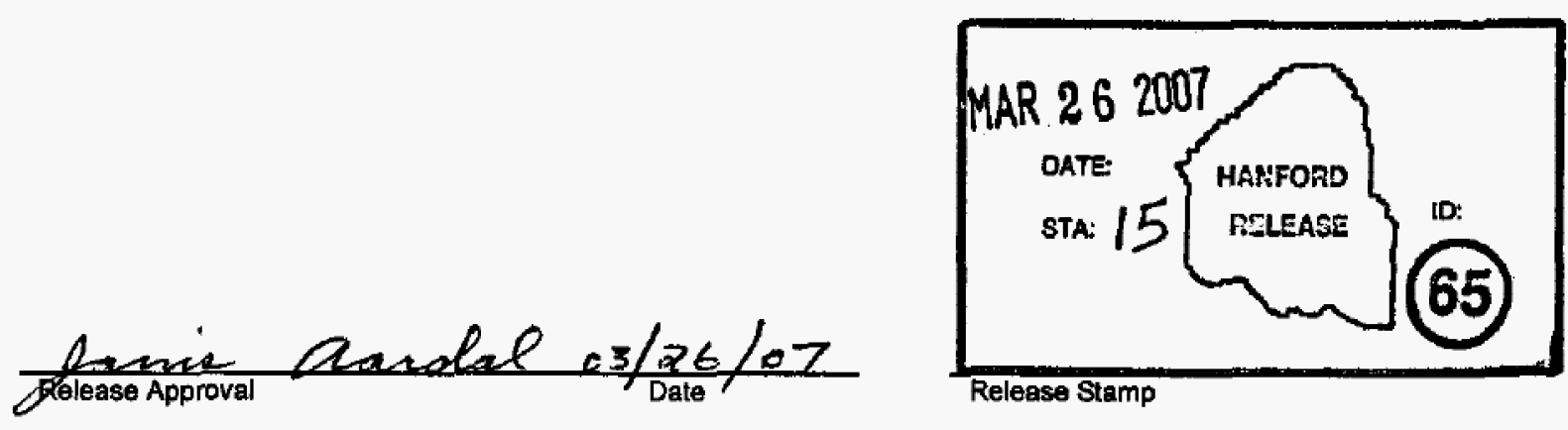

Approved For Public Release 


\title{
222-S LABORATORY FUME HOOD TESTING STUDY
}

\author{
B. H. Ruelas \\ CH2M HILL Hanford Group, Inc.
}

Date Published

March 2007

Prepared for the U.S. Department of Energy Office of River Protection

Contract No. DE-AC27-99RL14047

Approved for public release; distribution is unlimited 


\section{CONTENTS}

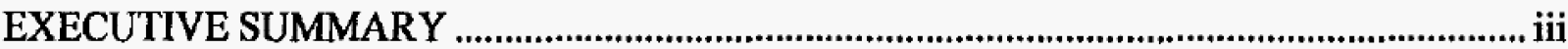

1. INTRODUCTION

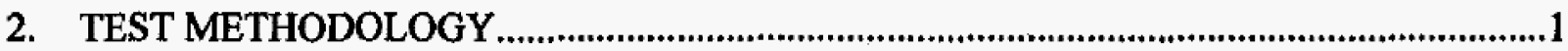

3. TEST RESULTS

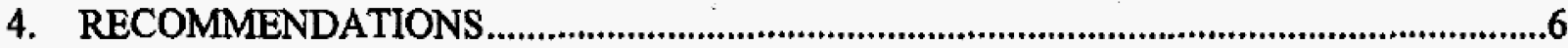

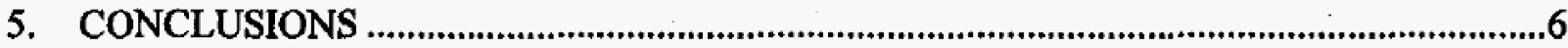

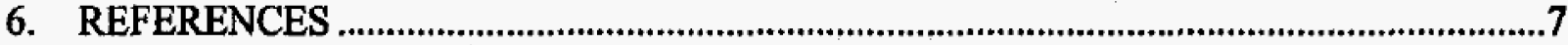

APPENDIX: LABORATORY FUME HOOD PERFORMANCE TESTING PLAN................. 46

\section{List of Figures}

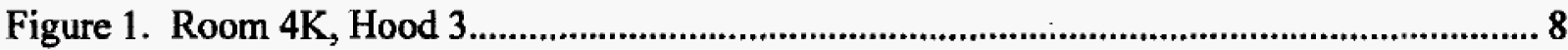

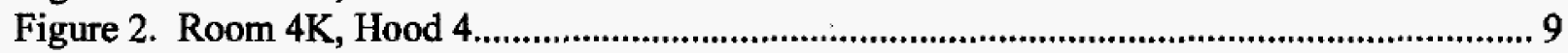

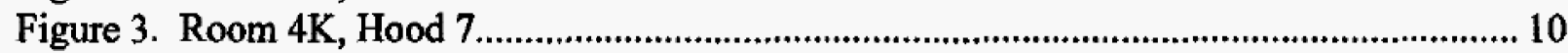

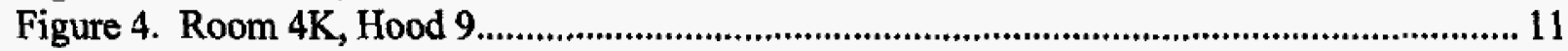

Figure 5. Room 4D, Hood 5.............................................................................................. 12

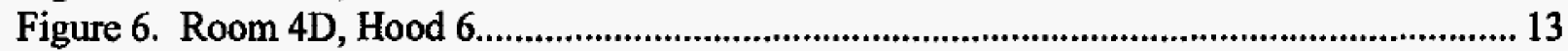

Figure 7. Room 4P, Hood 3. ............................................................................................... 14

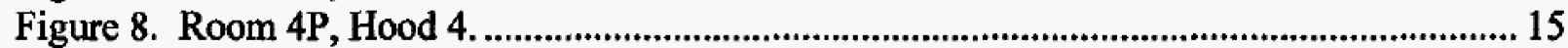

Figure 9. Room 4P, Hood 10 ........................................................................................... 16

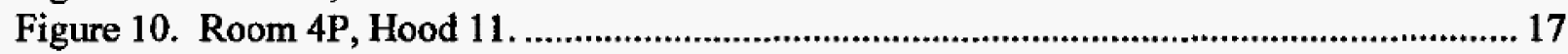

Figure 11. Room 1K, Hood 4........................................................................................... 18

Figure 12. Room 1D, Hood 4........................................................................................ 19

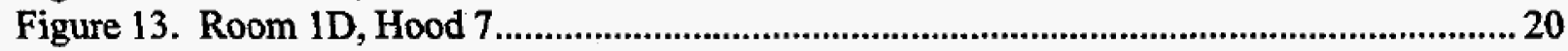

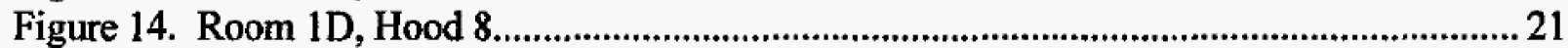

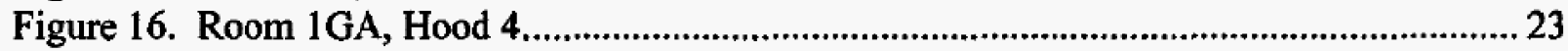

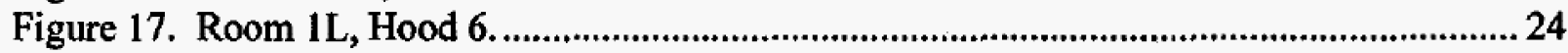

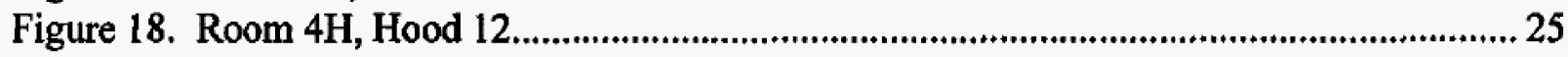

Figure 19. Room 4S, Hood 3. ............................................................................................. 26

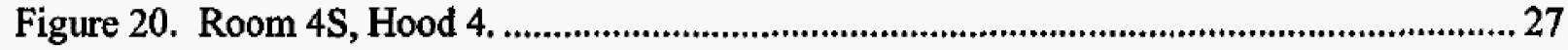

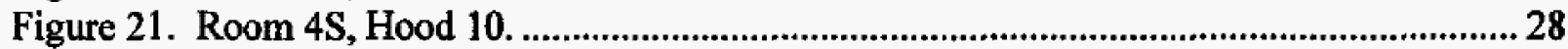

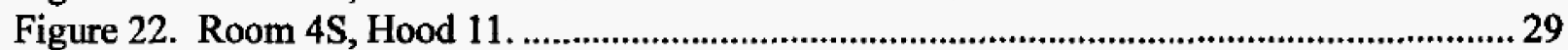

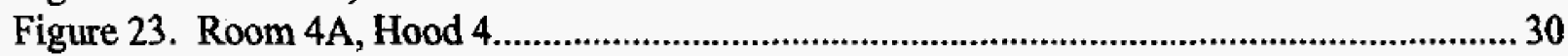

Figure 24. Room 4A, Hood 5.......................................................................................... 31

Figure 25. Room 4B, Hood 3................................................................................................ 32

Figure 26. Room 4B, Hood 5.............................................................................................. 33

Figure 27. Room 4C, Hood 1............................................................................................ 34

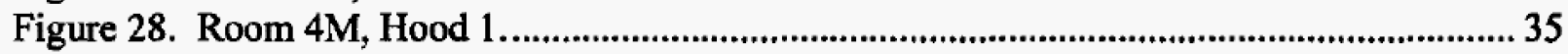

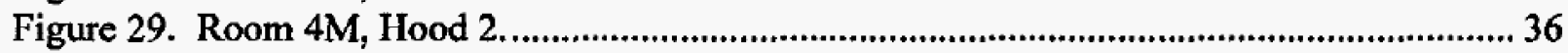

Figure 30. Room 4M, Hood 3.................................................................................................... 37

Figure 31. Room 4M, Hood 4.............................................................................................. 38

Figure 32. Room 4J, Hood 11........................................................................................ 39 


\section{RPP-RPT-32842, Rev. 0}

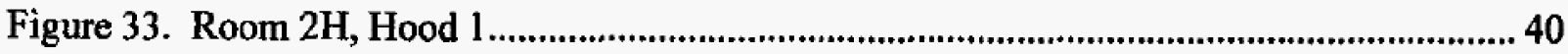

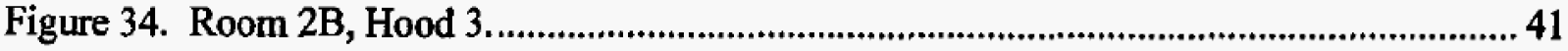

Figure 35. Room 4B, Hood 3 (RETEST). …………….......................................................... 42

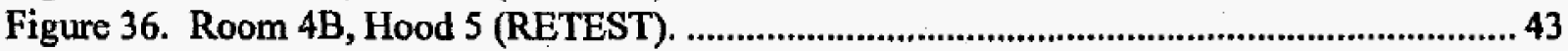

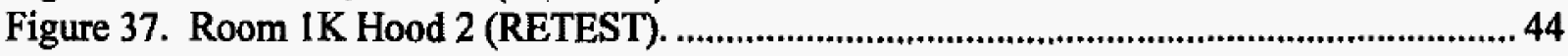

Figure 38. Room 1K, Hood 4 (RETEST) ................................................................................. 45

\section{List of Tables}

Table 1. Arm Port Fume Hood Test Results............................................................................... 3

Table 2. Open Face Fume Hood Test Results.......................................................................... 


\section{EXECUTIVE SUMMARY}

On October, 26, 2006, the performance of fume hood 2 in Room $1 \mathrm{~K}$ of the 222-S Laboratory was brought into question after employees detected odors in the room while mixing chemicals within the subject fume hood. Room 1K and fume hood 2 were placed on restricted access until testing could be performed to assess the performance of the fume hood.

Face velocity and smoke (flow visualization) testing of fume hood 2 was conducted on November 15, 2006, to rate the performance of the fume hood under varying conditions. Face velocity of the subject fume hood was found to be within normal operating parameters. Flow visualization testing revealed that airflow turbulence within the fume hood resulted in periodic reversal of vapors towards the front of the fume hood. Some of these vapors would then actually break the sash plane of the fume hood, reverse direction, and then flow back into the fume hood.

Based on testing observations, it was deemed appropriate to conduct further evaluations of other 222-S Laboratory fume hoods. Thirty-four fume hoods were identified as candidates for performance testing. Of the 34 candidate fume hoods, 13 were configured with arm port sashes while the remaining 21 had open face sashes. The majority of these fume hoods contained large pieces of analytical equipment or exhibited "as-used" conditions similar to fume hood 2 in Room 1K.

Based on performance testing results, an engineering evaluation was conducted for each of the candidate fume hoods. This evaluation established an initial performance rating for each fume hood based on a combination of the air velocity profile and flow visualization assessment.

Of the 13 arm port fume hoods tested, seven were rated as "Good" and the remaining six rated as "Fair." All fume hoods rated as "Fair" contained a significant amount of equipment or materials that caused a significant increase in turbulence that was normally observed in all the arm port fume hoods tested.

Of the 21 open-face fume hoods initially tested, 15 were rated as "Good," three rated as "Fair," and three rated as "Poor." All three of the fume hoods rated as "Fair" received their rating due to localized air turbulence caused by instruments positioned within 6 in. of the sash face. Each of the three fume hoods rated as "Poor" received their rating due to turbulence, slow clearing time, and the potential for airflow reversal caused by large solid objects placed close to the fume hood sash plane.

Improvements to fume hood performance ratings can be achieved by the repositioning of instrumentation or materials contained within the fume hood. For example, fume hood 2 in Room $1 \mathrm{~K}$ received an improved performance rating by removing excess laboratory items and positioning the remaining materials at least 6 in. back from the fume hood sash plane.

Flow characteristics can be improved by modifying support equipment features. The performance ratings for fume hoods 3 and 5 in Room 4B were raised from "Poor" to "Fair" by cutting openings in the lower section of the splash shields that were positioned just inside the fume hood sash planes. Other candidate fume hoods could show similar improved performance ratings with minor modifications. 


\section{INTRODUCTION}

The 222-S Laboratory contains 155 active fume hoods that are used to support analytical work with radioactive and/or toxic materials. Face velocities for these fume hoods are set and maintained based on many years of operating experience and guidance from the American Conference of Governmental Industrial Hygienists (ACGIH ${ }^{B}$ ) Industrial Ventilation: A Manual of Recommended Practice. Monthly testing is performed and documented to ensure that the face velocity of each fume hood remains within established parameters. In addition to this, laboratory personnel conduct all analytical activities using approved work practices to ensure safe fume hood operation.

On October 26, 2006, the performance of fume hood 2 in Room $1 \mathrm{~K}$ of the 222-S Laboratory was brought into question after employees detected odors in the room while mixing chemicals within the subject fume hood. Following this event, performance testing was conducted on fume hood 2. Results of the testing indicated that the large quantity of analytical equipment and materials contained within the fume hood caused airflow turbulence that led to periodic release of vapors into the surrounding area.

Based on the observations from the testing of fume hood 2 in Room $1 \mathrm{~K}$, a selected group of candidate fume hoods was identified for performance testing. These fume hoods contained large pieces of analytical equipment or congested work surfaces that could contribute to reduced fume hood performance.

\section{TEST METHODOLOGY}

The selected testing methods were adopted from ANSI/ASHRAE 110-1995, Method of Testing Performance of Laboratory Fume Hoods. The test methods used provided for a qualitative and quantitative evaluation of fume hood performance.

The quantitative evaluation consisted of air velocity measurements. These measurements were taken across the face of each fume hood utilizing a grid pattern established in accordance with Analytical Technical Services Maintenance Procedure 2S99003, "Open Face/Arm Port Hood Airflow Test, 222-S." The average of the velocity measurements was calculated, the highest and lowest readings noted, and a velocity profile generated.

The qualitative portion of the evaluation consisted of general, local, and large volume flow visualization testing. A mixture of dry ice and hot water was used to generate a visible "challenge vapor" for these tests. Direct observation as well as recording of digital video was utilized to render a determination on the ability of each fume hood to contain vapors in its "as-used" state. 
Based on flow visualization test results, performance ratings were established for each of the candidate fume hoods. These ratings and criteria are as follows:

$\underline{\text { Good }}$

Challenge vapors are adequately captured at the face of the fume hood and are drawn into the furne hood and exhausted. Quick clearance times are observed. Limited fume hood roll vortex. No visible escape of vapors at any time. Turbulence and eddying will be observed in arm port furme hoods between the arm port openings.

Fair

Some challenge vapors reverse flow and migrate toward the fume hood face but are recaptured and exhausted. Dead air spaces are present that would result in a slow migration of vapors toward the fume hood face but are again recaptured and exhausted. Limited turbulent vortex is observed. No visible escape of vapors at any time.

Poor

Challenge vapors reverse flow near the fume hood face. Dead air spaces are present that result in slow migration of vapors toward the fume hood face. Slow capture and clearance of challenge vapors. There is an observed potential for escape of vapors from the fume hood.

\section{Failure}

Challenge vapors migrate directly to the fume hood face and escape from the interior of the fume hood into the surrounding area.

\section{TEST RESULTS}

The data presented in Table 1 shows the average and minimum/maximum readings for face velocities, flow visualization test rating, and general comments applicable to each of the candidate arm port fume hoods.

Of the 13 arm port fume hoods tested, seven of these fume hoods received a "Good" performance rating. The remaining six arm port fume hoods received a "Fair" performance rating. It was noted during flow visualization testing that all arm port fume hoods exhibited varying degrees of turbulence between the arm ports and on either side of the arm ports next to the hood walls. Five of the six fume hoods rated as "Fair" contained a significant amount of equipment that was positioned in such a manner as to accentuate the inherent turbulence problem. Fume hood 1 in Room $2 \mathrm{H}$ received a "Fair" rating due to turbulence in the front section of the fume hood caused by poor housekeeping and less than adequate work practices within the fume hood (materials and equipment very close to the hood face). Fume hood 6 in Room 4D was found cluttered with numerous bagged items that were placed between and on top 
of analytical equipment. Despite the poor housekeeping, this fume hood received a performance rating of "Good."

Table 1. Arm Port Fume Hood Test Results.

\begin{tabular}{|l|c|c|c|c|c|}
\hline Room & Hood & $\begin{array}{c}\text { Average } \\
\text { Face } \\
\text { Velocity }\end{array}$ & $\begin{array}{c}\text { Maximum/Minimum } \\
\text { Face Velocity }\end{array}$ & $\begin{array}{c}\text { Performance } \\
\text { Rating }\end{array}$ & Comments \\
\hline 4D & 6 & 133 & $135 / 130$ & Good & Needs housekeeping. \\
\hline 4P & 10 & 130 & $137 / 125$ & Good & Clean work area. \\
\hline 1B & 9 & 133 & $137 / 129$ & Good & Equipment well placed. \\
\hline 1GA & 4 & 134 & $136 / 133$ & Good & Hood is well kept. \\
\hline 4C & 1 & 134 & $141 / 130$ & Good & Equipment well placed. \\
\hline 4A & 4 & 134 & $140 / 130$ & Good & $\begin{array}{l}\text { Minor turbulence in right } \\
\text { corner. }\end{array}$ \\
\hline 4A & 5 & 135 & $142 / 131$ & Good & $\begin{array}{l}\text { Minor turbulence in right } \\
\text { corner. }\end{array}$ \\
\hline 4D & 5 & 134 & $139 / 128$ & Fair & $\begin{array}{l}\text { Excessive equipment for this } \\
\text { type of hood. }\end{array}$ \\
\hline 1D & 4 & 131 & $132 / 130$ & Fair & $\begin{array}{l}\text { Excessive equipment for this } \\
\text { type of hood. }\end{array}$ \\
\hline 1D & 7 & 134 & $138 / 132$ & Fair & $\begin{array}{l}\text { Excessive equipment for this } \\
\text { type of hood }\end{array}$ \\
\hline 1D & 8 & 134 & $145 / 126$ & Fair & $\begin{array}{l}\text { Excessive equipment for this } \\
\text { type of hood }\end{array}$ \\
\hline 4J & 11 & 133 & $134 / 131$ & Fair & $\begin{array}{l}\text { Equipment position causing } \\
\text { turbulence. }\end{array}$ \\
\hline 2H & 1 & 135 & $141 / 132$ & Fair & $\begin{array}{l}\text { Very cluttered. Materials } \\
\text { too close to sash plane. }\end{array}$ \\
\hline
\end{tabular}

The average face velocity for 222-S Laboratory fume hoods is required to be 125 to 140 feet per minute (FPM).

${ }^{b}$ Performance rating from test plan.

Note: All values listed are in FPM.

The data presented in Table 2 show the average and minimum/maximum readings for face velocities, flow visualization test rating, and general comments applicable to each of the candidate open face fume hoods.

Of the 21 open face fume hoods initially tested, 15 fume hoods received a performance rating of "Good." Three fume hoods received a performance rating of "Fair" and three fume hoods received a performance rating of "Poor." All three of the fume hoods rated as "Fair" received this rating due to some localized turbulence and swirling of vapors caused by instruments positioned within 6 in. of the sash face.

Fume hoods 3 and 5 in Room 4B received "Poor" ratings due to splash shields that were positioned just inside the sash faces (within 2 to 3 in.). Velocity profiles for these two fume hoods show a significant decrease in face velocities at the splash shield locations. A very slow clearing time of vapors was observed for both of these fume hoods during flow visualization testing. Following initial performance testing, the splash shields were modified by cutting circular openings in the lower portion of each shield. Velocity and flow visualization testing was again performed for these two fume hoods. This time, a significant improvement in airflow 
around and through the shields was observed with some expected turbulence. These two fume hoods received a revised performance rating of "Fair."

Hood 4 in Room 1K was rated "Poor" due to a large solid support platform that was positioned in the center front section of this fume hood. Flow visualization testing indicated that a potential for escape of vapors from this fume hood might occur if personnel attempted to utilize the limited work surface directly in front of the solid support platform. Following initial performance testing, the solid support platform contained within this fume hood was replaced by an open support platform. Velocity and flow visualization testing was repeated for this hood. The performance rating for this fume hood remained at "Poor" due to some turbulence and reversal of airflow at the fume hood face between the new platform and some containers providing secondary containment for bottled chemicals. This fume hood has been removed from service until such time as the observed performance issues can be corrected.

Finally, fume hood 2 in Room $1 \mathrm{~K}$ was retested after excess materials and items had been either removed or moved back at least 6 in. from the fume hood face plane. Some swirling on the left side wall of the fume hood was observed. This could be attributed to a couple of bottled chemicals and the tight fit of an instrument located against the left wall. Based on the results of the retest, this fume hood would now be performance rated as "Fair." 
Table 2. Open Face Fume Hood Test Results.

\begin{tabular}{|c|c|c|c|c|c|}
\hline Room & Hood & $\begin{array}{l}\text { Average } \\
\text { Face } \\
\text { Velocity }\end{array}$ & $\begin{array}{l}\text { Maximum/ } \\
\text { Minimum } \\
\text { Face Velocity }\end{array}$ & $\begin{array}{l}\text { Performance } \\
\text { Rating }\end{array}$ & Comments \\
\hline $4 K$ & 3 & 130 & $170 / 91$ & Good & Large equipment is raised. \\
\hline $4 \mathrm{~K}$ & 4 & 134 & $185 / 90$ & Good & Large equipment is raised. \\
\hline $4 \mathrm{~K}$ & 7 & 131 & $180 / 91$ & Good & Large equipment is raised. \\
\hline $4 \mathrm{~K}$ & 9 & 135 & $169 / 114$ & Good & Large equipment is raised. \\
\hline $4 \mathrm{P}$ & 3 & 132 & $153 / 98$ & Good & Large equipment is raised. \\
\hline $4 \mathrm{P}$ & 4 & 132 & $150 / 113$ & Good & Equipment is well placed. \\
\hline $4 \mathrm{P}$ & 11 & 132 & $143 / 124$ & Good & Equipment is well placed. \\
\hline $1 \mathrm{~L}$ & 6 & 134 & $153 / 124$ & Good & Modified open face. \\
\hline $4 \mathrm{H}$ & 12 & $13 \overline{5}$ & $195 / 61$ & Good & $\begin{array}{l}\text { Very slight amount of swirling on left side } \\
\text { in front of instrument. }\end{array}$ \\
\hline $4 S$ & 3 & 135 & $150 / 109$ & Good & Connected to hood 4. \\
\hline $4 \mathrm{~S}$ & 10 & 133 & $143 / 122$ & Good & Connected to hood 11. \\
\hline $4 S$ & 11 & 134 & $145 / 128$ & Good & Equipment well placed. \\
\hline $4 \mathrm{M}$ & 2 & $13 \overline{5}$ & $150 / 120$ & Good & Good airflow pattern. \\
\hline $4 \mathrm{M}$ & 3 & 132 & $147 / 108$ & Good & Good airflow pattern. \\
\hline $2 \mathrm{~B}$ & 3 & 132 & $190 / 51$ & Good & Strong airflow pattem. \\
\hline $4 \mathrm{M}$ & 1 & 133 & $165 / 70$ & Fair & $\begin{array}{l}\text { Some swirling directly in front of } \\
\text { instrument. }\end{array}$ \\
\hline $4 M$ & 4 & 130 & $162 / 110$ & Fair & $\begin{array}{l}\text { Some turbulence on right side in front of } \\
\text { instrument. }\end{array}$ \\
\hline $4 S$ & 4 & 130 & $153 / 115$ & Fair & $\begin{array}{l}\text { Turbulence in front of "Caliper" unit. } \\
\text { Some reverse flow observed. }\end{array}$ \\
\hline $1 \mathbf{K}$ & 4 & 134 & $155 / 46$ & Poor & $\begin{array}{l}\text { Large solid platform causing turbulence } \\
\text { and reverse airflow towards hood face. }\end{array}$ \\
\hline $4 B$ & 3 & 132 & $183 / 21$ & Poor & $\begin{array}{l}\text { Splash shield blocking inlet flow. Slow } \\
\text { clearing time between shield and hot plate. }\end{array}$ \\
\hline $4 B$ & 5 & 135 & $177 / 54$ & Poor & $\begin{array}{l}\text { Splash shield blocking inlet flow. Slow } \\
\text { clearing time between shield and hot plate. }\end{array}$ \\
\hline $4 B$ & 3 & 134 & $183 / 42$ & Fair & $\begin{array}{l}\text { RETEST-Splash shield modified. } \\
\text { Airflow pattern improved through, around, } \\
\text { and behind shield. }\end{array}$ \\
\hline 4B & 5 & 128 & $190 / 52$ & Fair & $\begin{array}{l}\text { RETEST - Splash shield modified. } \\
\text { Airflow pattern improved through, around, } \\
\text { and behind shield. }\end{array}$ \\
\hline $1 \mathrm{~K}$ & 2 & 138 & $148 / 131$ & Fair & $\begin{array}{l}\text { RETEST - Good airflow distribution in } \\
\text { hood, some swirling observed on left side } \\
\text { near wall of hood. }\end{array}$ \\
\hline $1 \mathrm{~K}$ & 4 & 133 & $146 / 121$ & Poor & $\begin{array}{l}\text { RETEST - Turbulence and reverse airflow } \\
\text { still observed near fume hood face. }\end{array}$ \\
\hline
\end{tabular}

"The average face velocity for 222-S Laboratory fume hoods is required to be 125 to 140 feet per minute (FPM).

${ }^{b}$ Performance rating from test plan.

Note: All values listed are in FPM. 
Figures 1 through 38 provide a comparison of fume hood face velocity profiles with photographs of the corresponding hoods showing the position of equipment and materials that were contained within each hood at the time of testing.

\section{RECOMMENDATIONS}

Equipment should always be placed as deep into the hood as possible and at least 6 in. back from the sash plane.

Whenever possible, large equipment should be elevated 2 to 3 in. above the work surface to allow airflow under and around the equipment.

The amount of equipment and materials in a hood should be limited. No more than $50 \%$ of the work surface should be taken up by equipment, apparatus, or large obstructions.

Sufficient space should be provided on the sides of equipment and laboratory materials placed in fume hoods. This will improve airflow patterns by reducing turbulence and swirling next to the fume hood wall.

On open face hoods, the sash height should be lowered, when possible, to improve capture of vapors. Some fume hoods in Room $4 \mathrm{~S}$ are operated with a reduced sash opening.

Adjustment of rear baffles on some of the hoods should be considered to improve the flow characteristics of the hood. Fume hoods 2 and 4 in Room $1 \mathrm{~K}$ might be candidates for baffle adjustment to obtain an increased flow across the working surfaces.

\section{CONCLUSIONS}

The "dry ice vapor challenge" test proved to be very effective in visualizing hood flow characteristics while minimizing waste generation and disruption of analytical processes. It was demonstrated to be the method of choice for flow visualization testing within fume hoods containing sensitive analytical instrumentation.

Prior to placement of large analytical equipment into a hood, face velocity and flow visualization testing should be performed to determine the performance characteristics of the hood in the "asinstalled" condition. All testing should be repeated after placement of the equipment into the hood to ensure that hood performance has not deteriorated significantly in the "as-used" state.

Some correlation was observed between the fume hood face velocity profiles and flow visualization performance testing, particularly with fume hoods 3 and 5 in Room 4B. Because this correlation was not consistent, there is justifiable argument for performing flow visualization testing for all questionable situations. 
Arm port fume hoods should not be used for analytical work that requires the use of large instruments or results in congested working surfaces. The inherent turbulence observed in all arm port fume hoods tested is increased significantly by these conditions. The reduced performance ratings for all three arm port fume hoods in Room 1D can be attributed to these conditions.

Regardless of fume hood performance rating, consideration must be made with regard to the toxicological properties of the materials being handled or are anticipated to be handled within any fume hood. A facility safety representative should be consulted to evaluate fume hood conditions and all proposed operations.

\section{REFERENCES}

222-S Maintenance Procedure 2S99003, Rev, 4-0, "Open Face/Arm Port Hood Airflow Test, 222-S," Analytical Technical Services, CH2M HILL Hanford Group, Inc., Richland, Washington.

ACGIH®, 1988, Industrial Ventilation: A Manual of Recommended Practice, $20^{\text {th }}$ Edition, American Conference of Governmental Hygienists, Cincinnati, Ohio.

ANSI/ASHRAE 110-1995, "Method of Testing Performance of Laboratory Fume Hoods," American National Standards Institute, New York, New York.

Interoffice Memo, N. L. Kirner to J. L. Heinemann and B. H. Ruelas, "Smoke Testing Room 1K at 222-S Laboratory," 7S600-NLK-06-009, dated December 5, 2006. 
RPP-RPT-32842, Rev. 0

Figure 1. Room 4K, Hood 3.

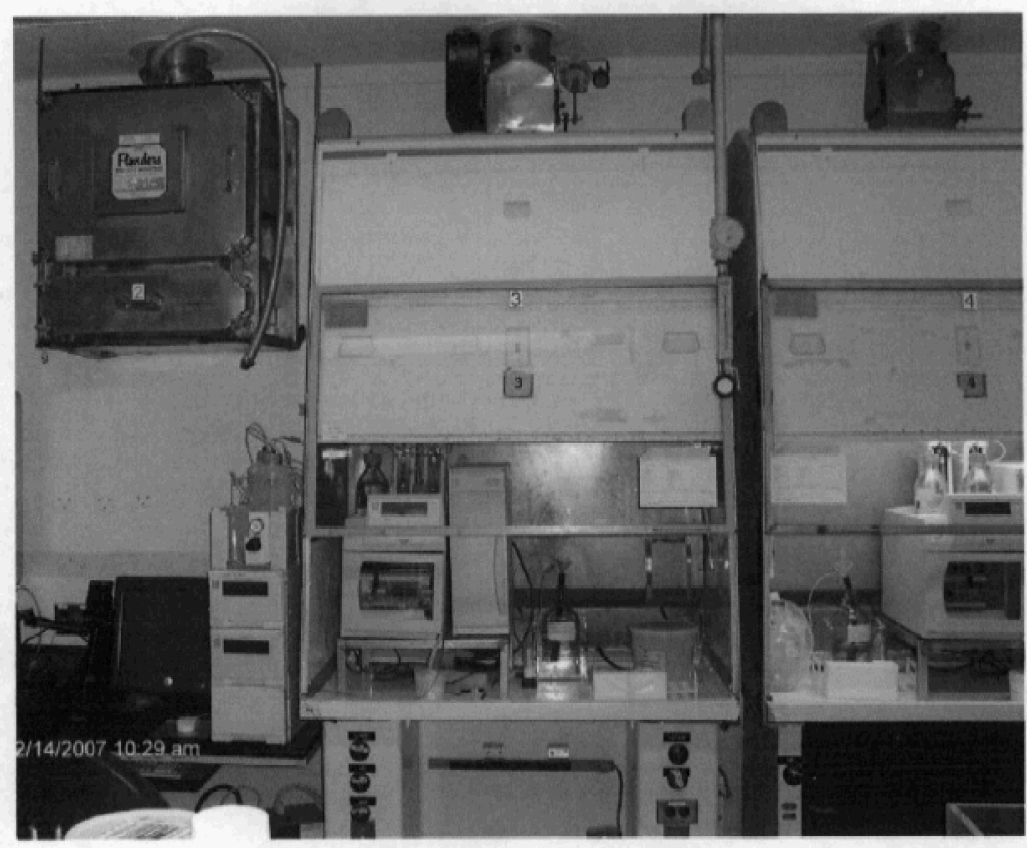

\section{SASH}

\begin{tabular}{|c|c|c|c|c|c|}
\hline 128 & 125 & 146 & 170 & \\
\hline 91 & 103 & 137 & 130 & \\
\hline 105 & 150 & 135 & 122 & \\
\hline 146 & 118 & 140 & 140 & \\
\hline
\end{tabular}

Face Velocity Profile (values are in FPM)

ROOM NO. $\underline{4 \mathrm{~K}}$

HOOD NO. $\underline{3}$

PERFORMANCE RATING: GOOD

Note: Flanders Bag Out Housing is a product of Flanders Corporation, St. Petersburg, Florida. 
RPP-RPT-32842, Rev. 0

Figure 2. Room 4K, Hood 4.

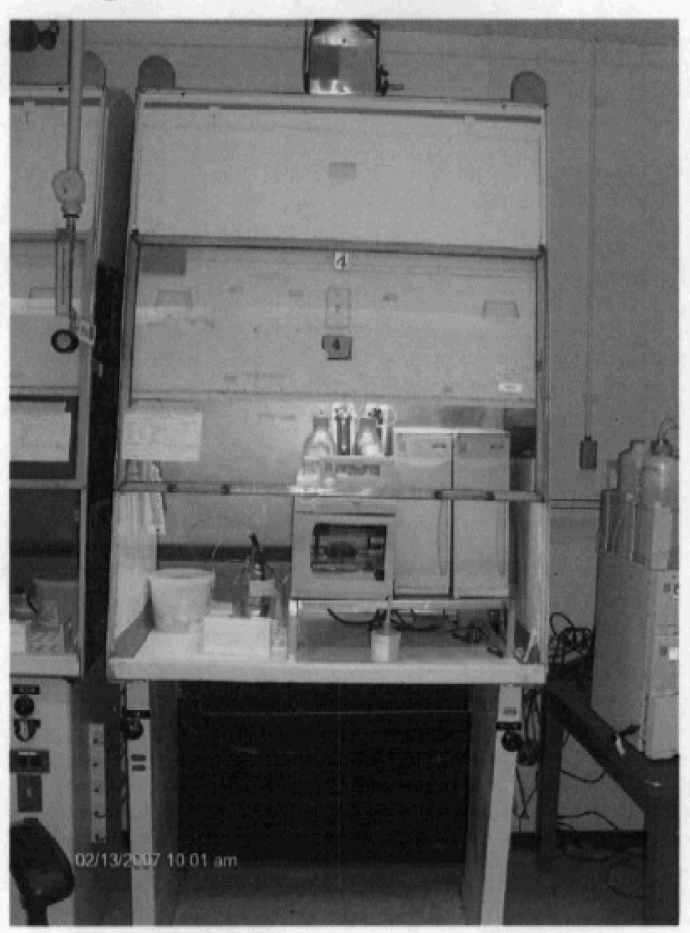

SASH

\begin{tabular}{|c|c|c|c|}
\hline 185 & 146 & 146 & 170 \\
\hline 160 & 170 & 92 & 95 \\
\hline 150 & 122 & 90 & 125 \\
\hline 150 & 120 & 110 & 125 \\
\hline
\end{tabular}

Face Velocity Profile (values are in FPM)

ROOM NO. $4 \mathrm{~K}$

HOOD NO. $\quad 4$

PERFORMANCE RATING: GOOD 
RPP-RPT-32842, Rev. 0

Figure 3. Room 4K, Hood 7.
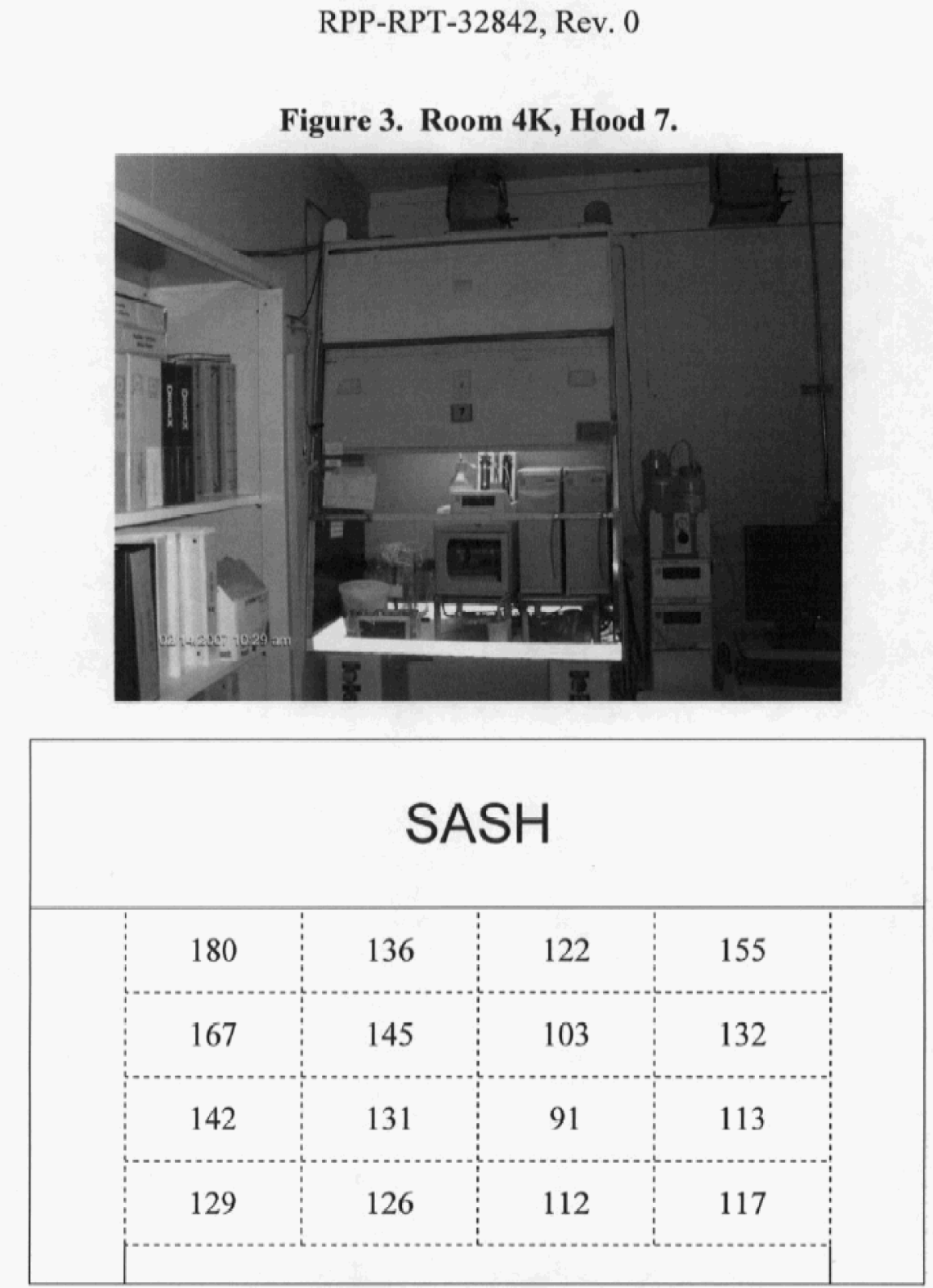

Face Velocity Profile (values are in FPM)

ROOM NO. $4 \mathrm{~K}$

HOOD NO. $\quad 7$

PERFORMANCE RATING: GOOD

K 
RPP-RPT-32842, Rev. 0

Figure 4. Room 4K, Hood 9.

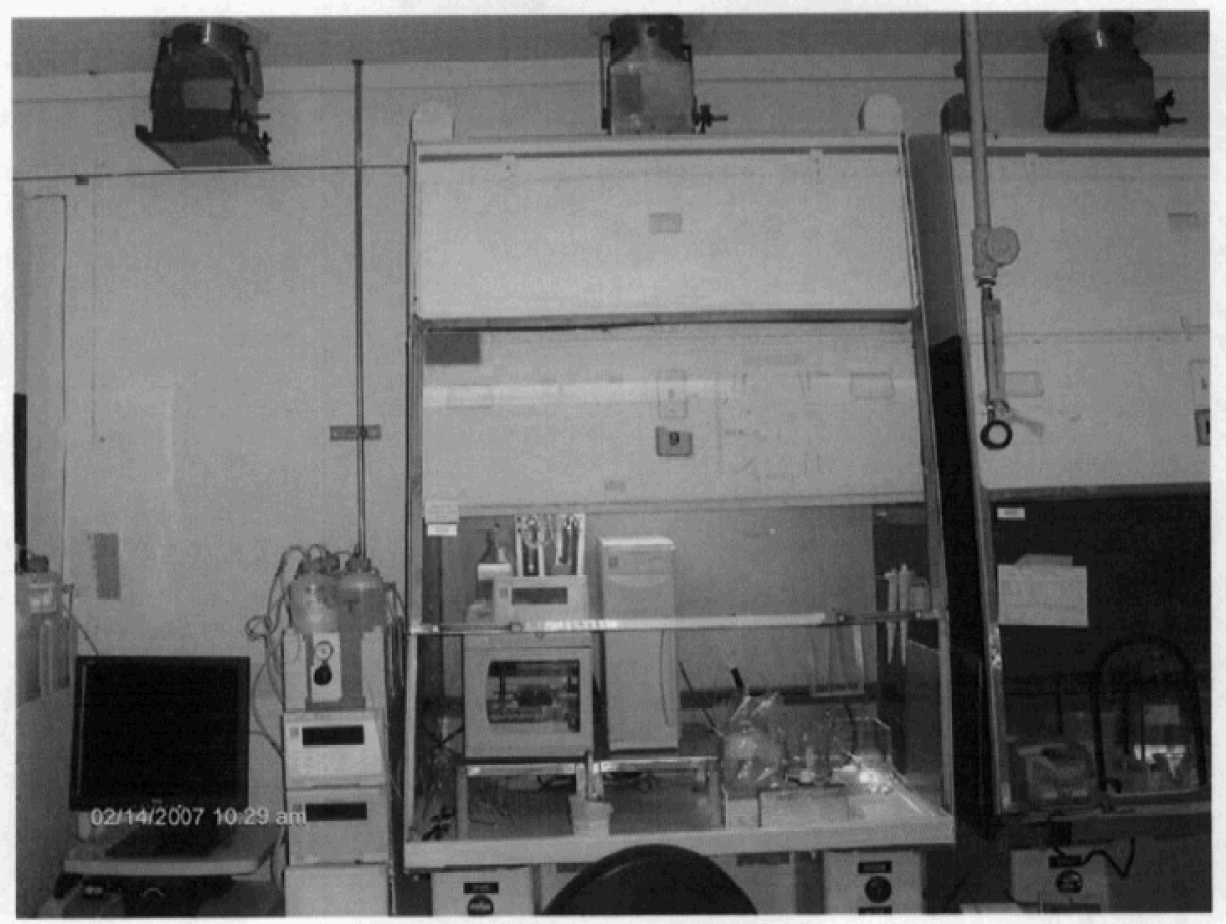

\begin{tabular}{|c|c|c|c|}
\hline 169 & 133 & 124 & 120 \\
\hline 158 & 132 & 130 & 130 \\
\hline 154 & 114 & 127 & 129 \\
\hline 162 & 122 & 126 & 126 \\
\hline
\end{tabular}

Face Velocity Profile (values are in FPM)

ROOM NO. $\underline{4 \mathrm{~K}}$

HOOD NO. $\underline{9}$

PERFORMANCE RATING: GOOD 
RPP-RPT-32842, Rev. 0

Figure 5. Room 4D, Hood 5.
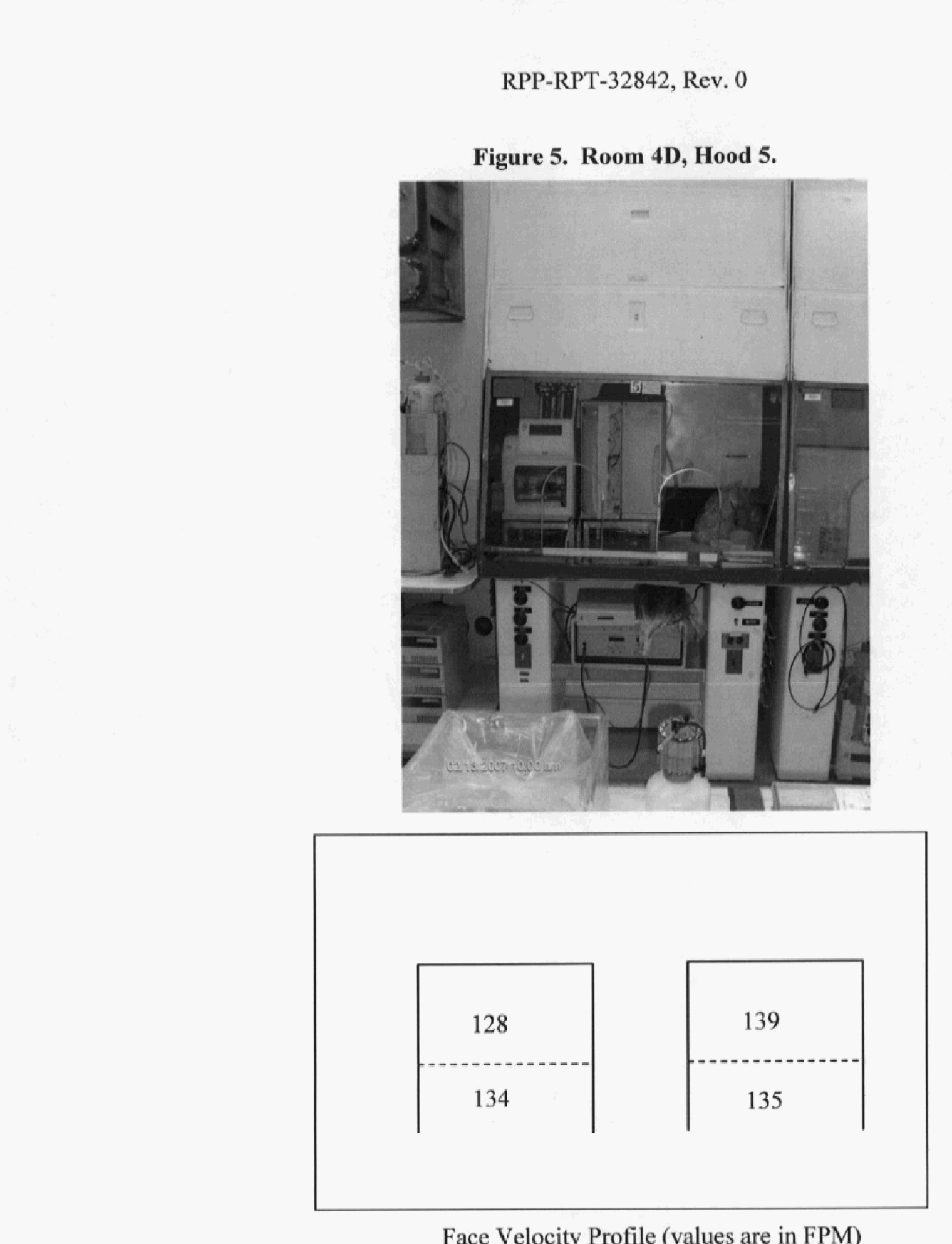

Face Velocity Profile (values are in FPM)

ROOM NO. 4D

HOOD NO. $\underline{5}$

PERFORMANCE RATING: FAIR

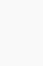

\section{PERTORMANCE RATING: BAIR}


RPP-RPT-32842, Rev. 0

Figure 7. Room 4P, Hood 3.
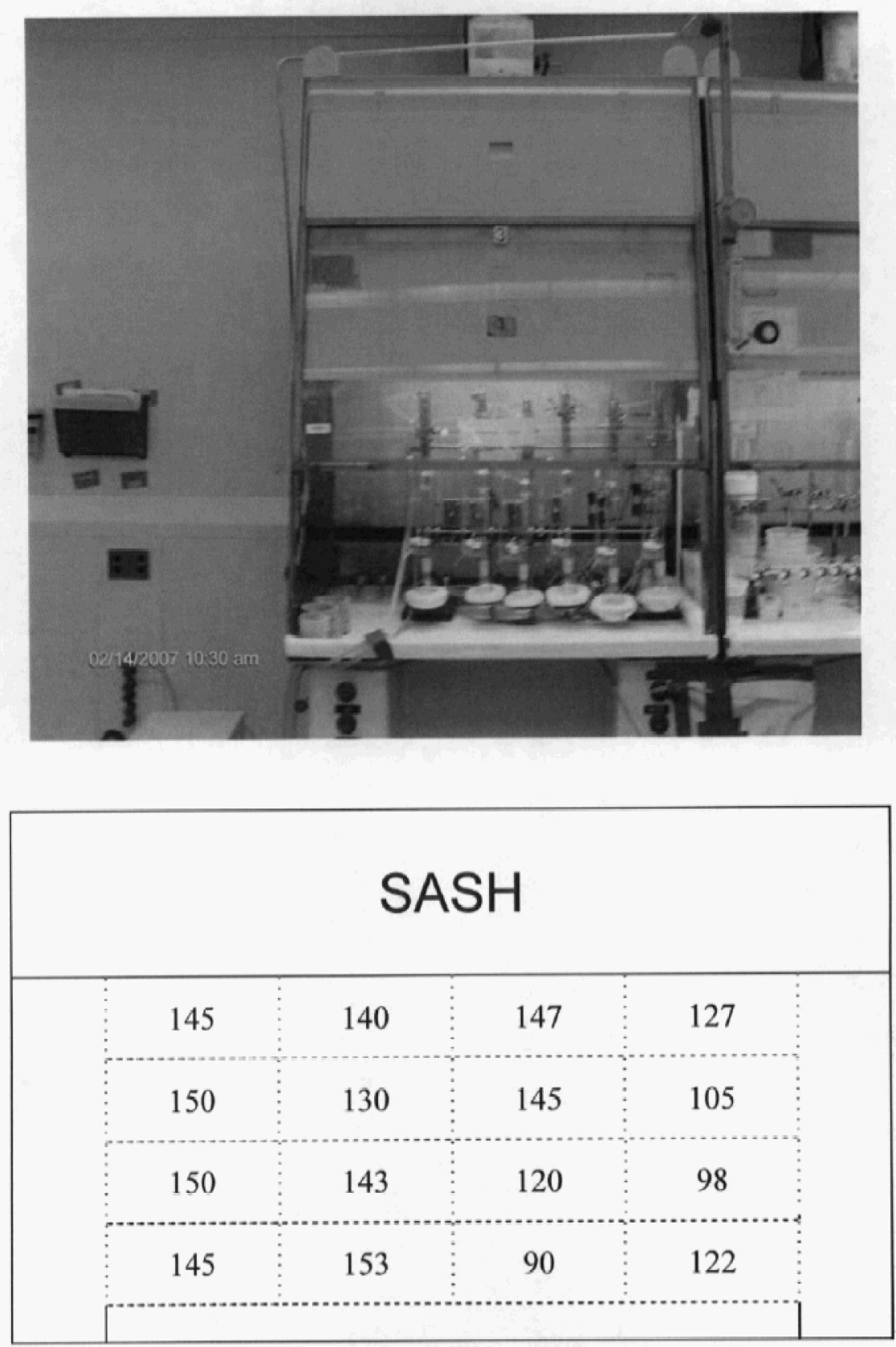

Face Velocity Profile (values are in FPM)

ROOM NO. 4 P

HOOD NO. $\underline{3}$

PERFORMANCE RATING: GOOD 
RPP-RPT-32842, Rev. 0

Figure 8. Room 4P, Hood 4.

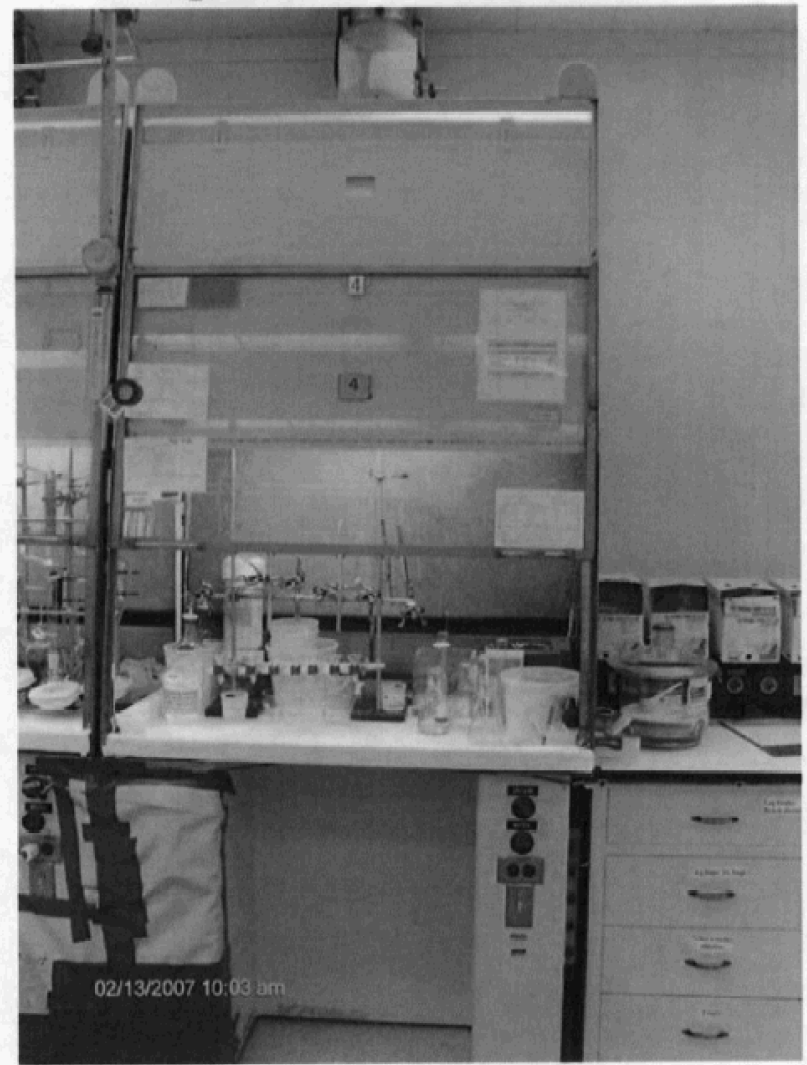

\section{SASH}

\begin{tabular}{|c|c|c|c|c|}
\hline 140 & 130 & 123 & 126 \\
\hline & 142 & 115 & 126 & 136 \\
\hline 148 & 122 & 113 & 136 \\
\hline & 150 & 145 & 135 & 132 \\
\hline
\end{tabular}

Face Velocity Profile (values are in FPM)

ROOM NO. $\underline{4 \mathrm{P}}$

HOOD NO. 4

PERFORMANCE RATING： GOOD 
RPP-RPT-32842, Rev. 0

Figure 9. Room 4P, Hood 10.
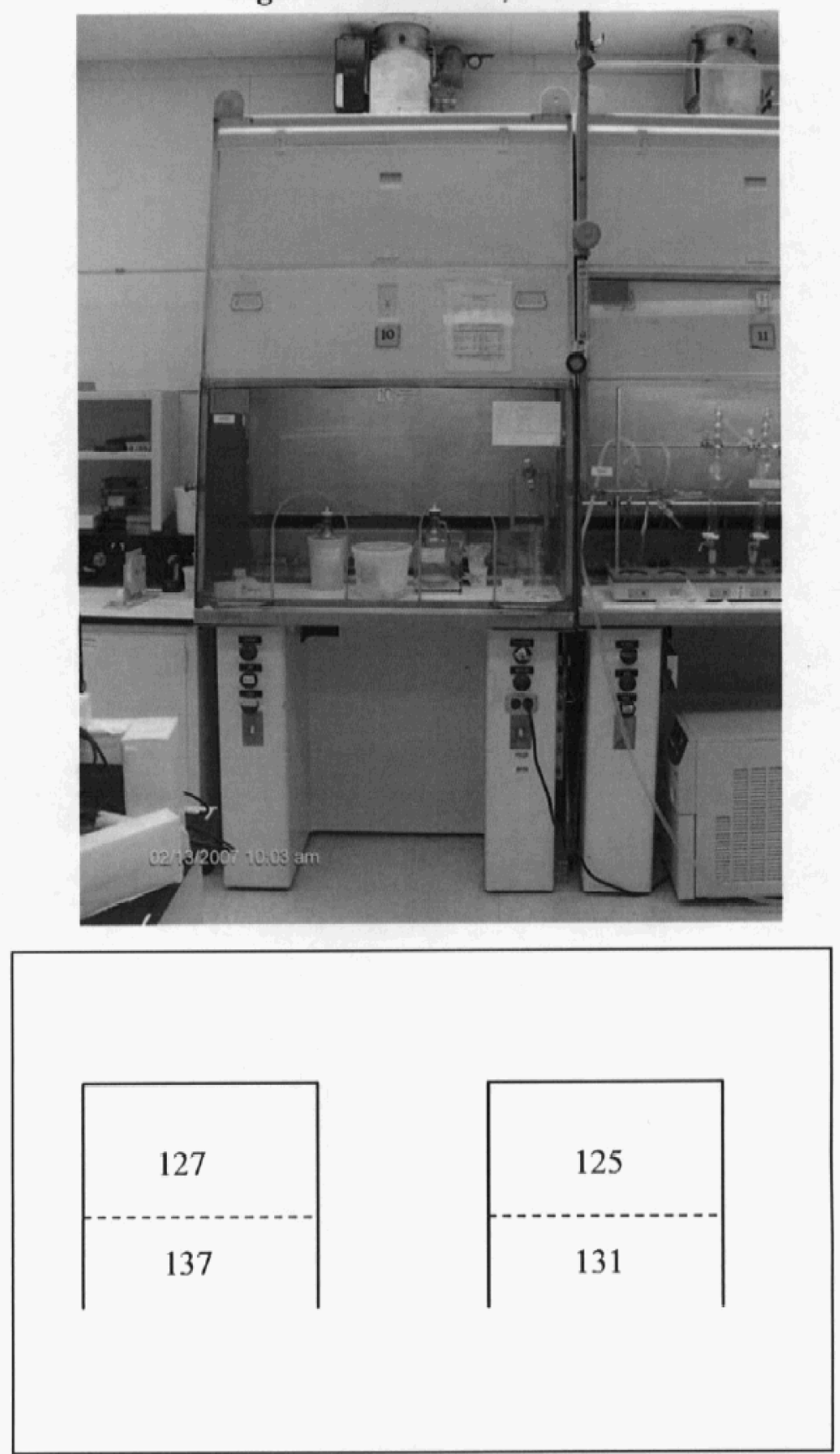

Face Velocity Profile (values are in FPM)

ROOM NO. $\underline{4 \mathrm{P}}$

HOOD NO. 10

PERFORMANCE RATING: GOOD

\author{
Face Velocity Profile (values are in FPM)
}

ROOMNO. 
RPP-RPT-32842, Rev. 0

Figure 10. Room 4P, Hood 11.
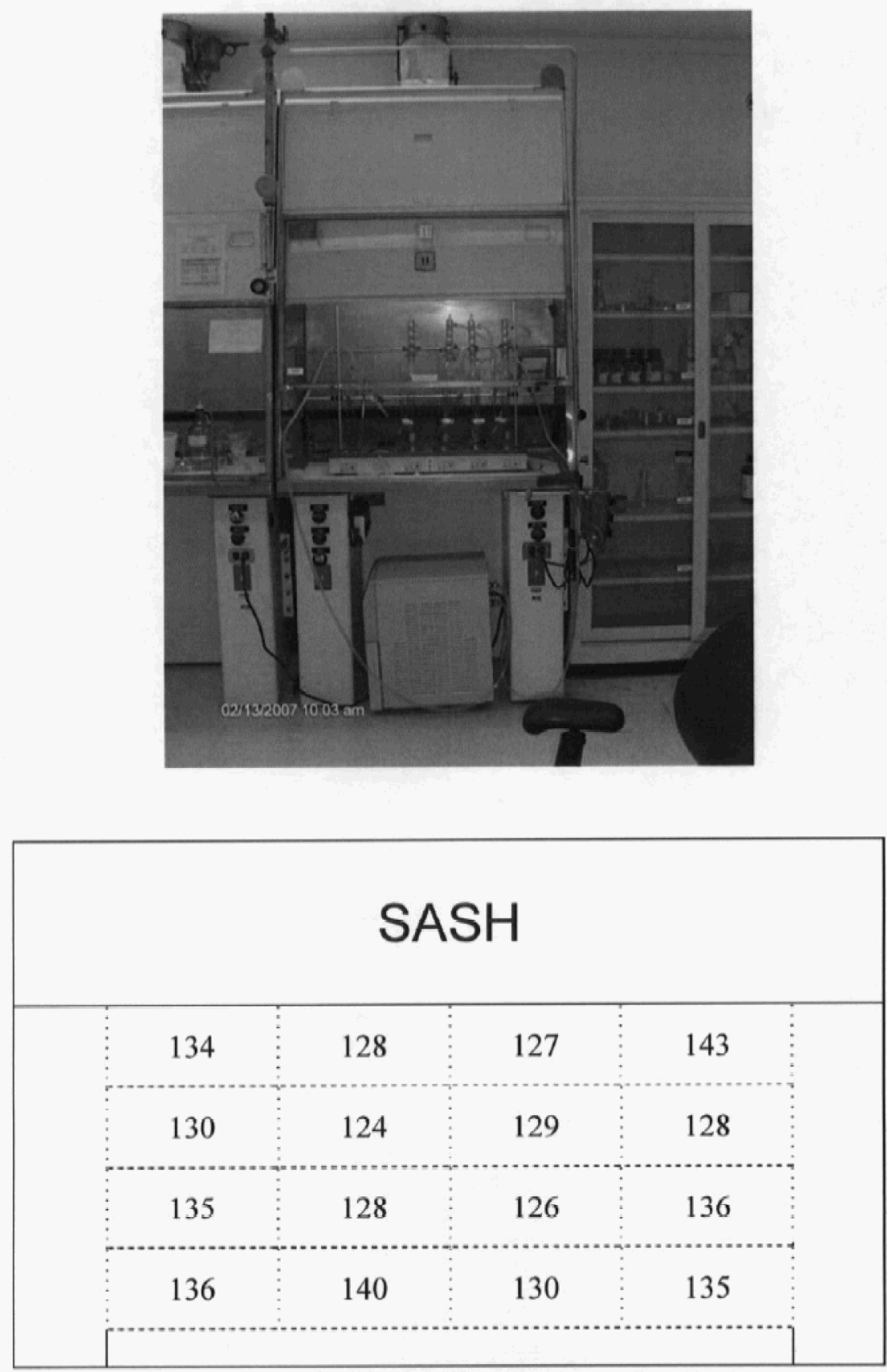

Face Velocity Profile (values are in FPM)

ROOM NO. 4ㄹ

HOOD NO. $\underline{11}$

PERFORMANCE RATING: GOOD 
RPP-RPT-32842, Rev. 0

Figure 11. Room 1K, Hood 4.

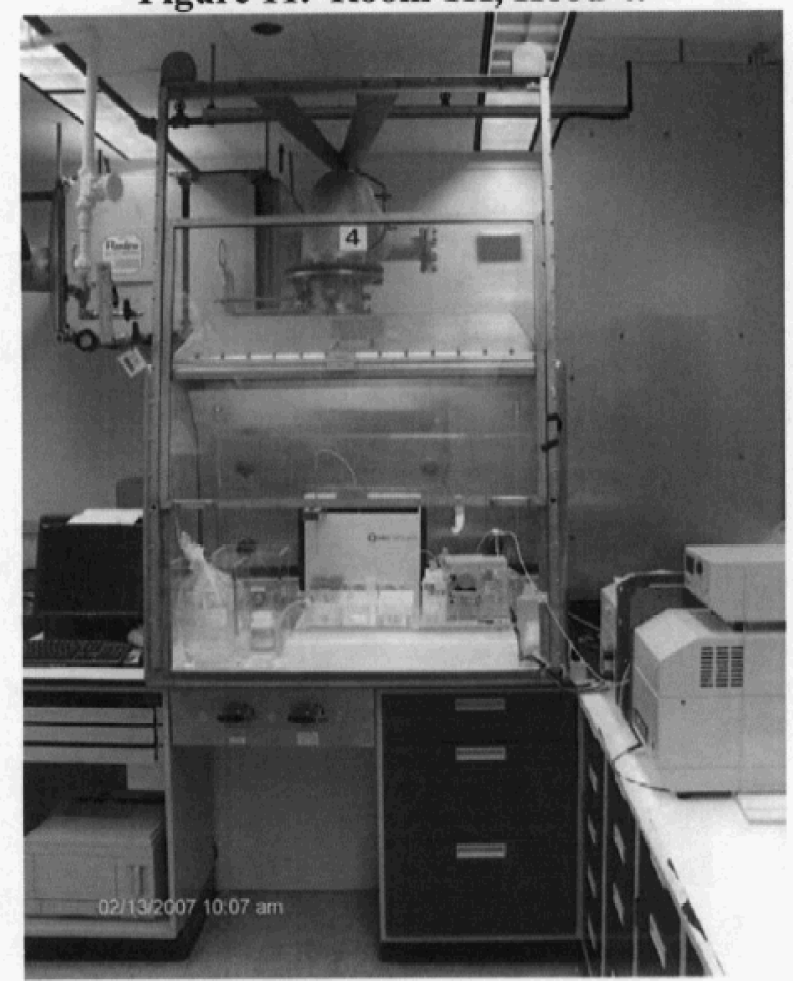

\section{SASH}

\begin{tabular}{|lll|l|l|l|l|}
\hline & 150 & 130 & 120 & 136 & $\vdots$ \\
\hline & 143 & 131 & 122 & 136 & $\vdots$ \\
\hline & 123 & 146 & 145 & 160 & $\vdots$ \\
\hline & 154 & 155 & 150 & 46 & $\vdots$ \\
\hline
\end{tabular}

Face Velocity Profile (values are in FPM)

ROOM NO. $\underline{1 \mathrm{~K}}$

HOOD NO. $\underline{4}$

PERFORMANCE RATING: GOOD

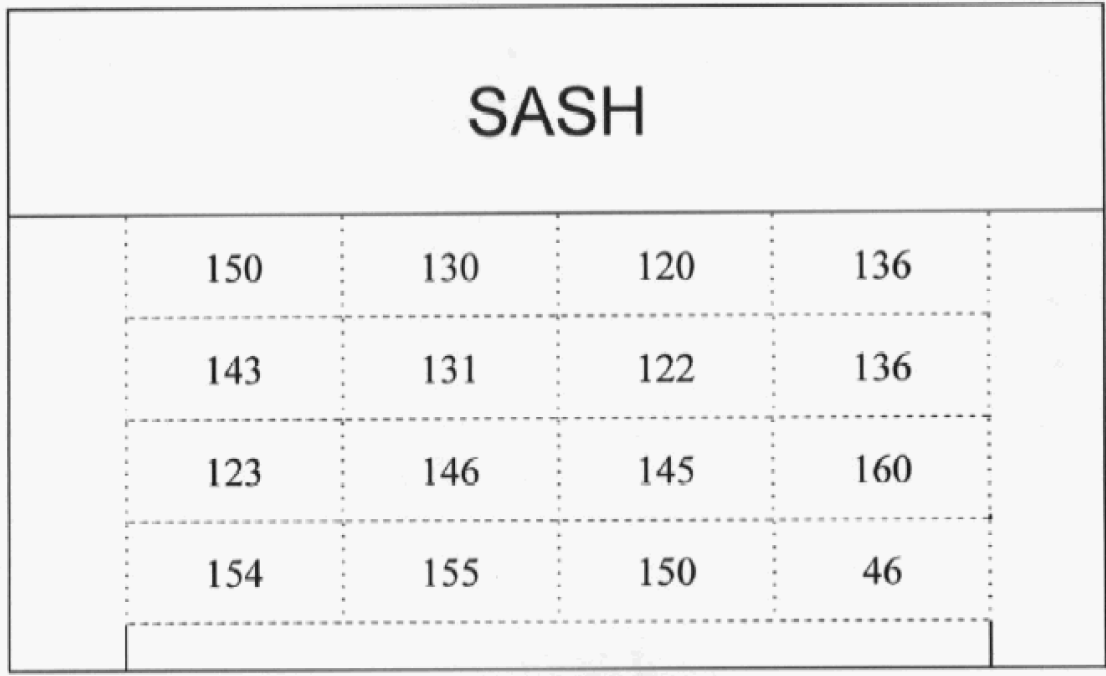

Face Velocily Profle (values are in FPM) 


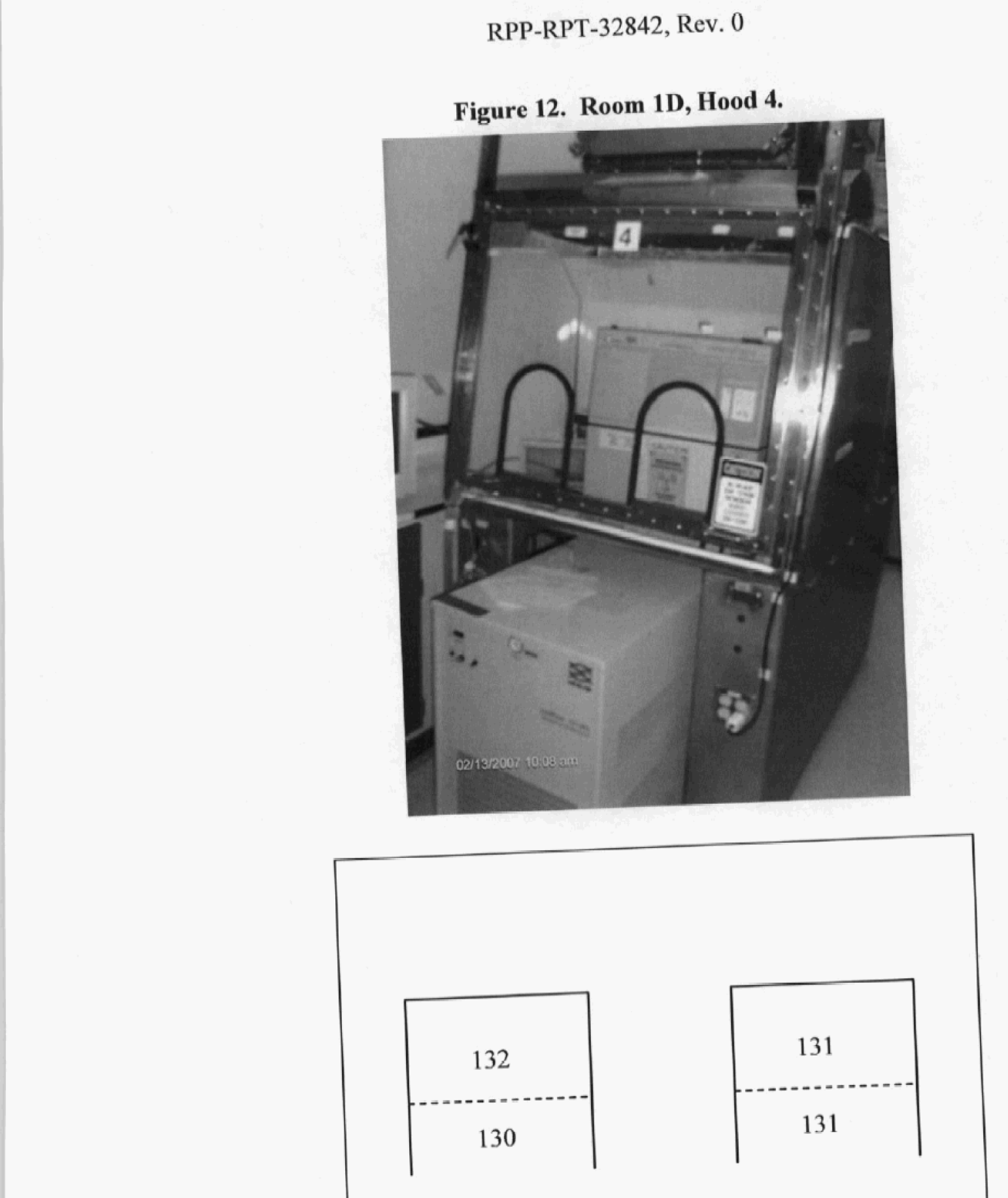

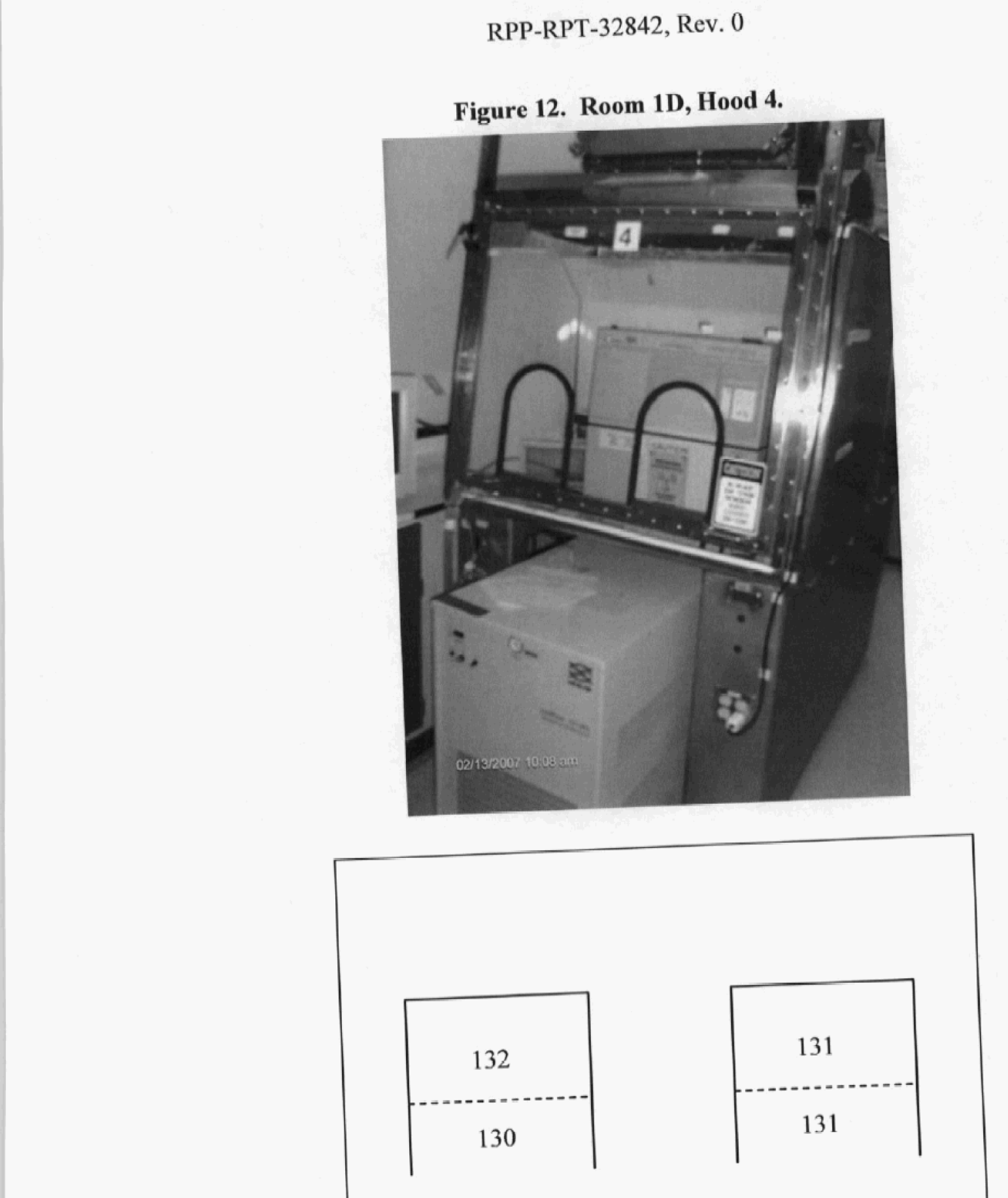
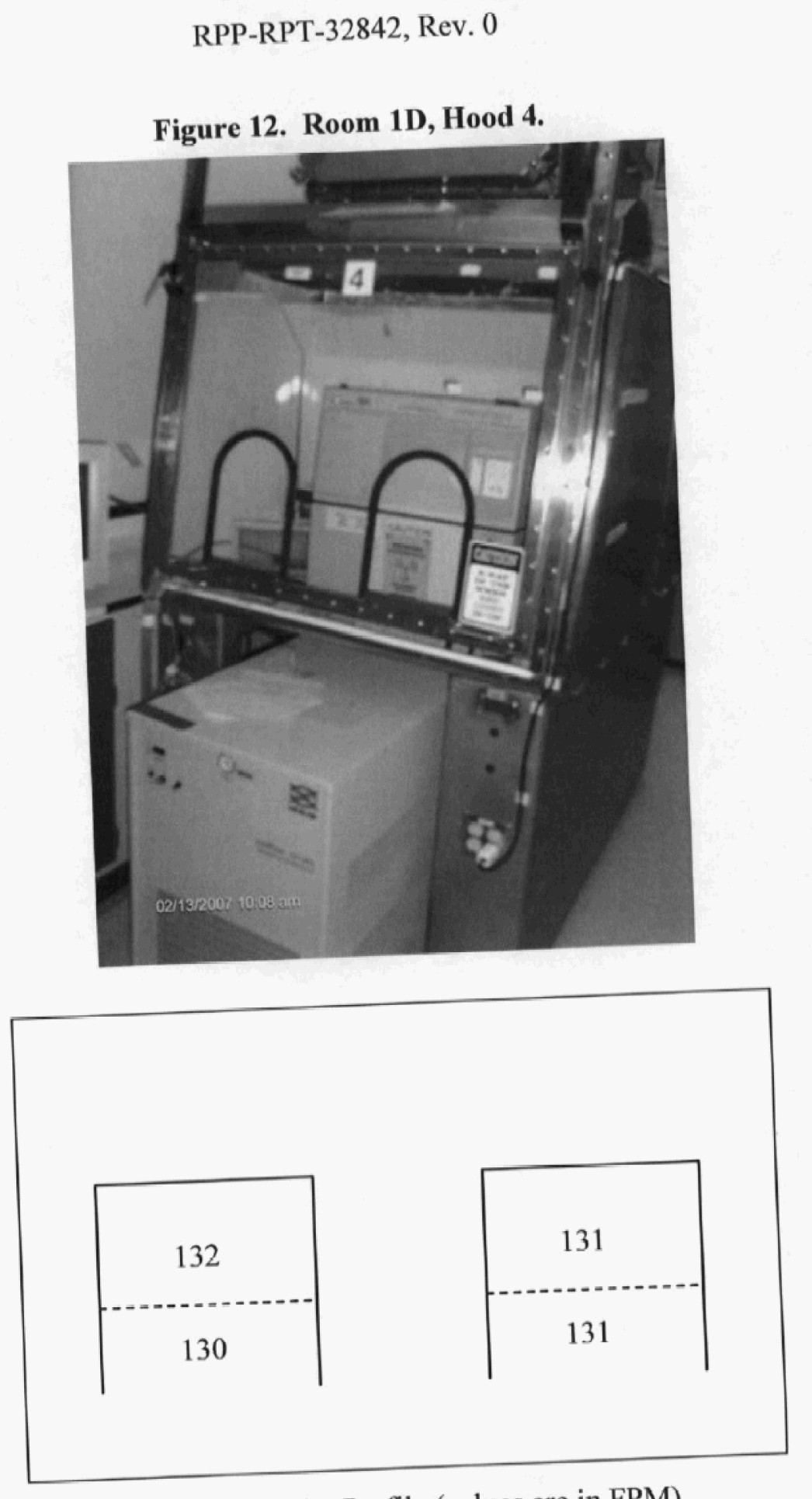

Face Velocity Profile (values are in FPM)

ROOM NO. 1D

ROOD NO. $\underline{4}$
PERFORMANCE RATING: FAIR

ROOD NO. $\underline{4}$
PERFORMANCE RATING: FAIR

Face Velocity Profile (values are in
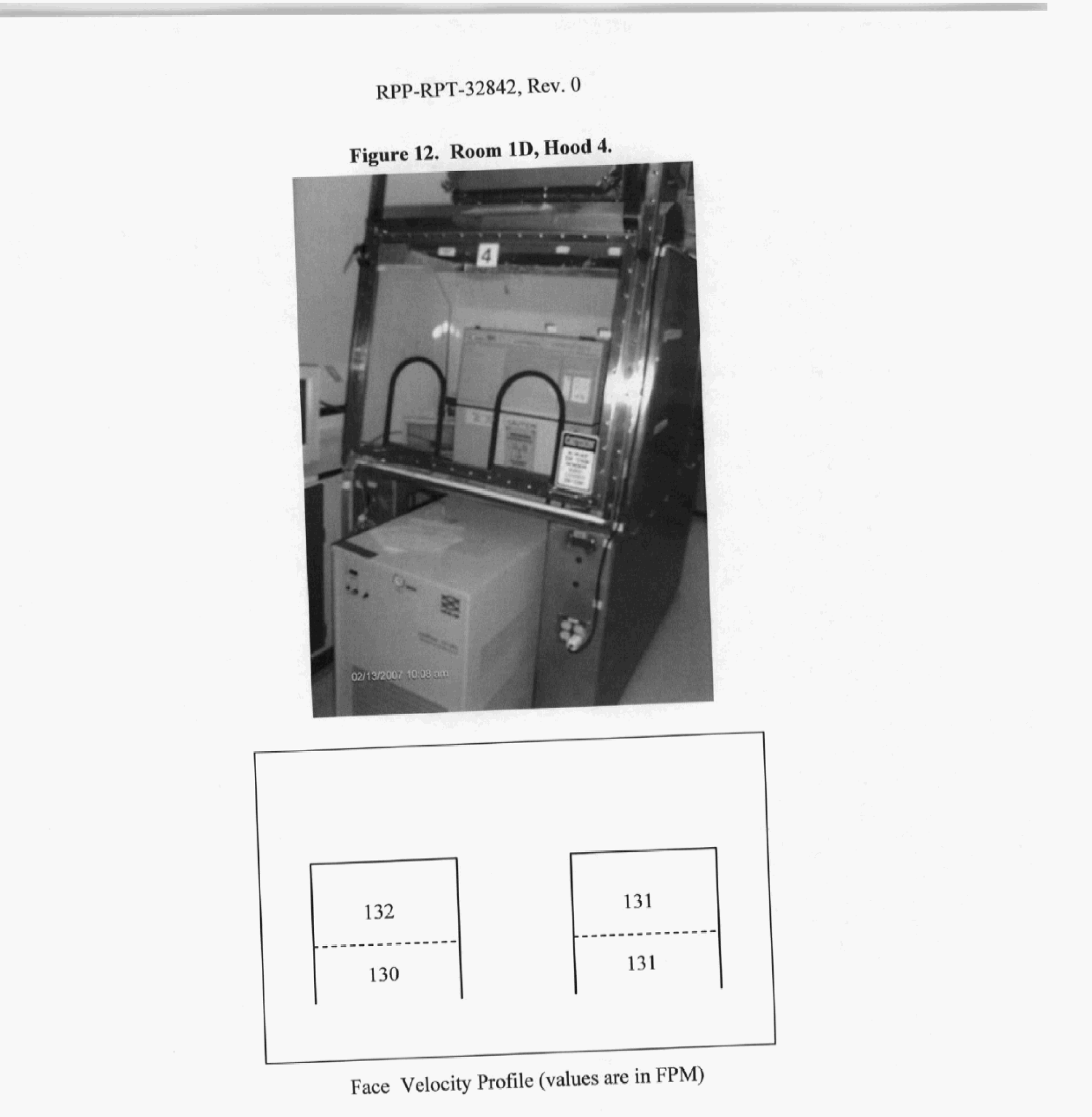


$$
\text { RPP-RPT-32842, Rev. } 0
$$

Figure 13. Room 1D, Hood 7.
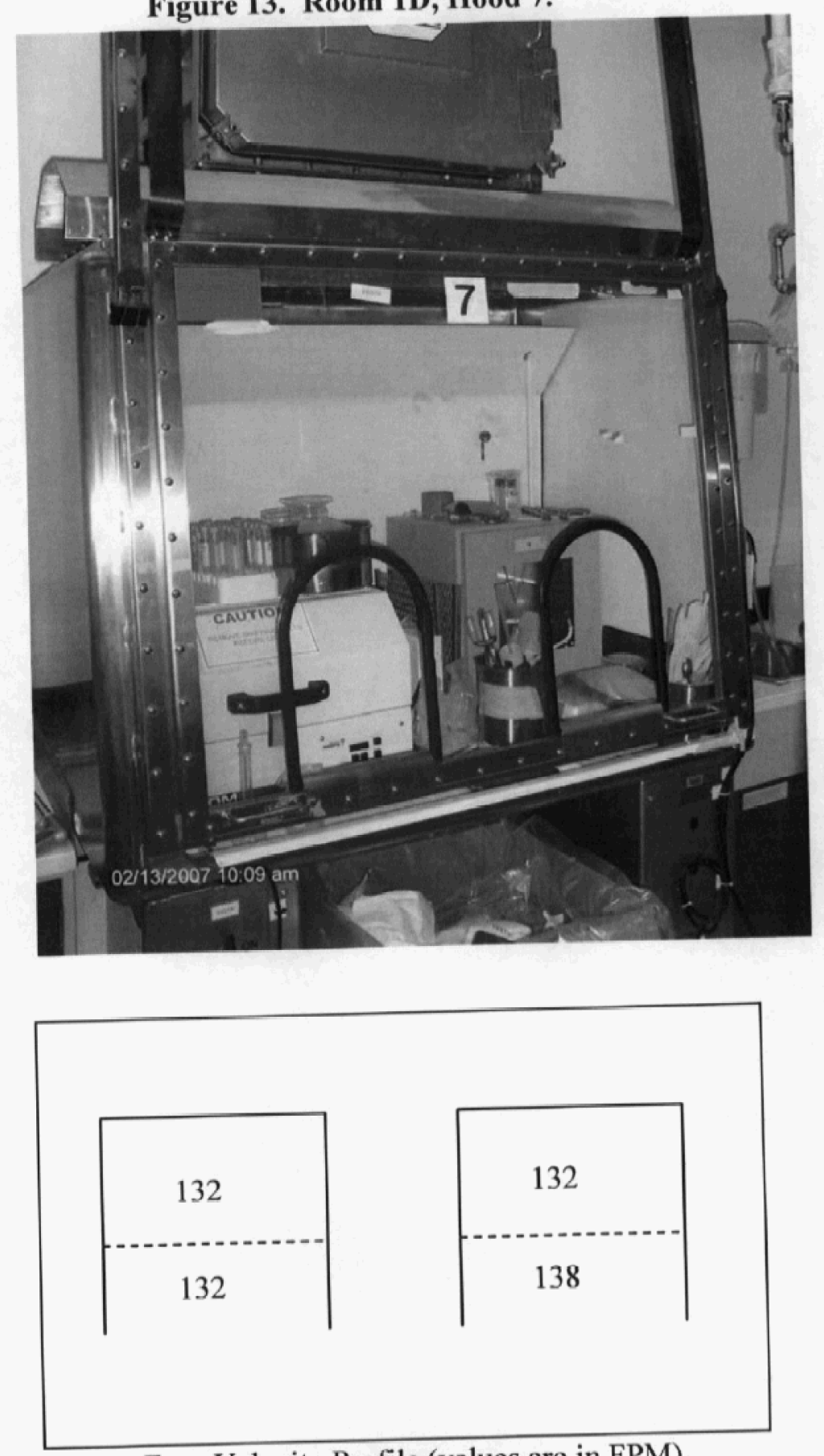

Face Velocity Profile (values are in FPM)

ROOM NO. $\underline{1 \mathrm{D}}$

HOOD NO. 7

PERFORMANCE RATING: FAIR 


\section{RPP-RPT-32842, Rev. 0}

Figure 14. Room 1D, Hood 8.
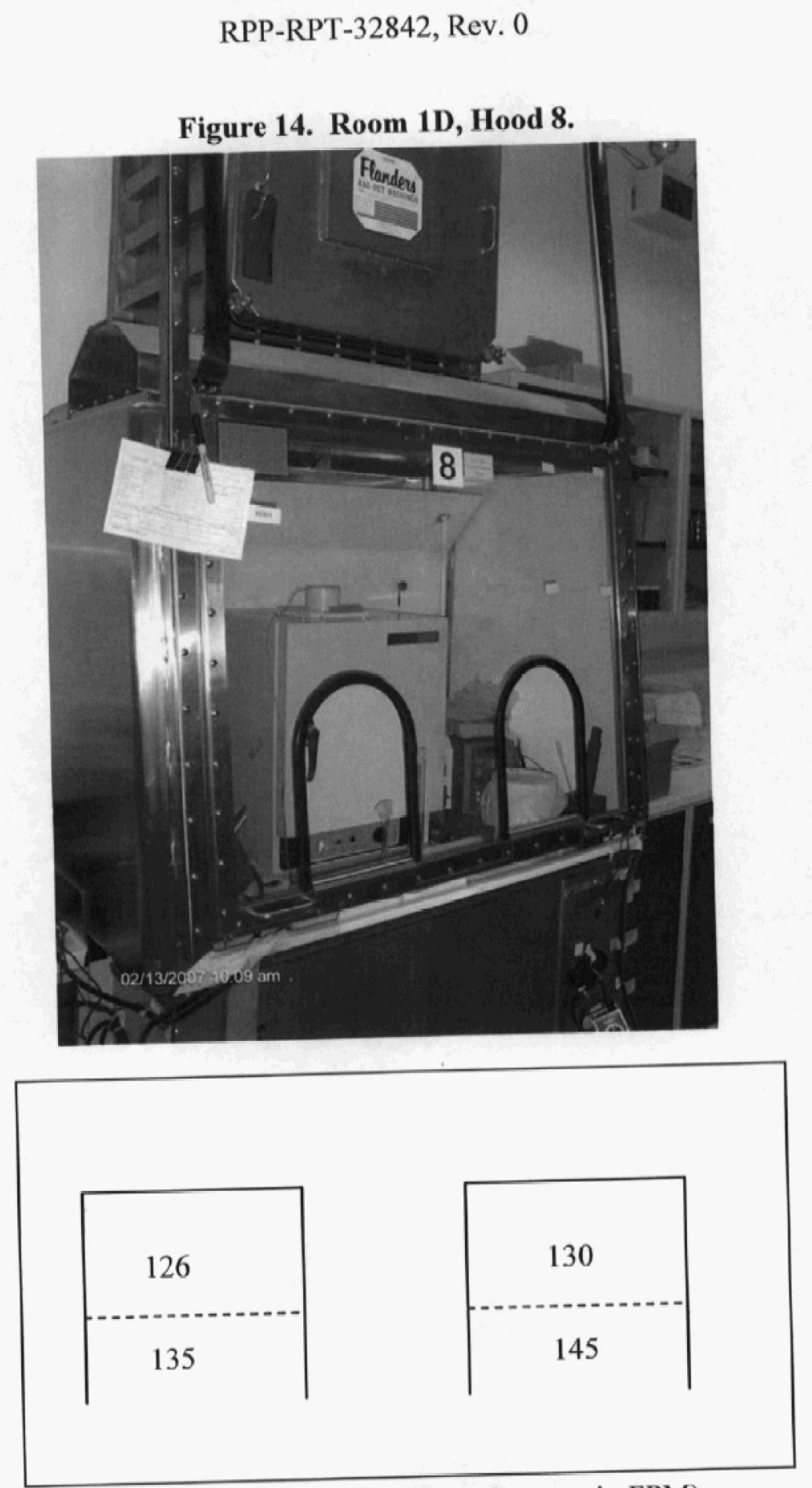

Face Velocity Profile (values are in FPM)

\footnotetext{
Face Velocily Profile (values are in FPM)
}

\footnotetext{
ROOMNO. 1D

HOOD NO. $\underline{8}$

PERFORMANCE RATING: FAIR

ROOMNO.

\section{PERTORMANCE RATING:}

8
}

(n)

$$
\text { . }
$$


RPP-RPT-32842, Rev. 0

Figure 15. Room 1B, Hood 9.
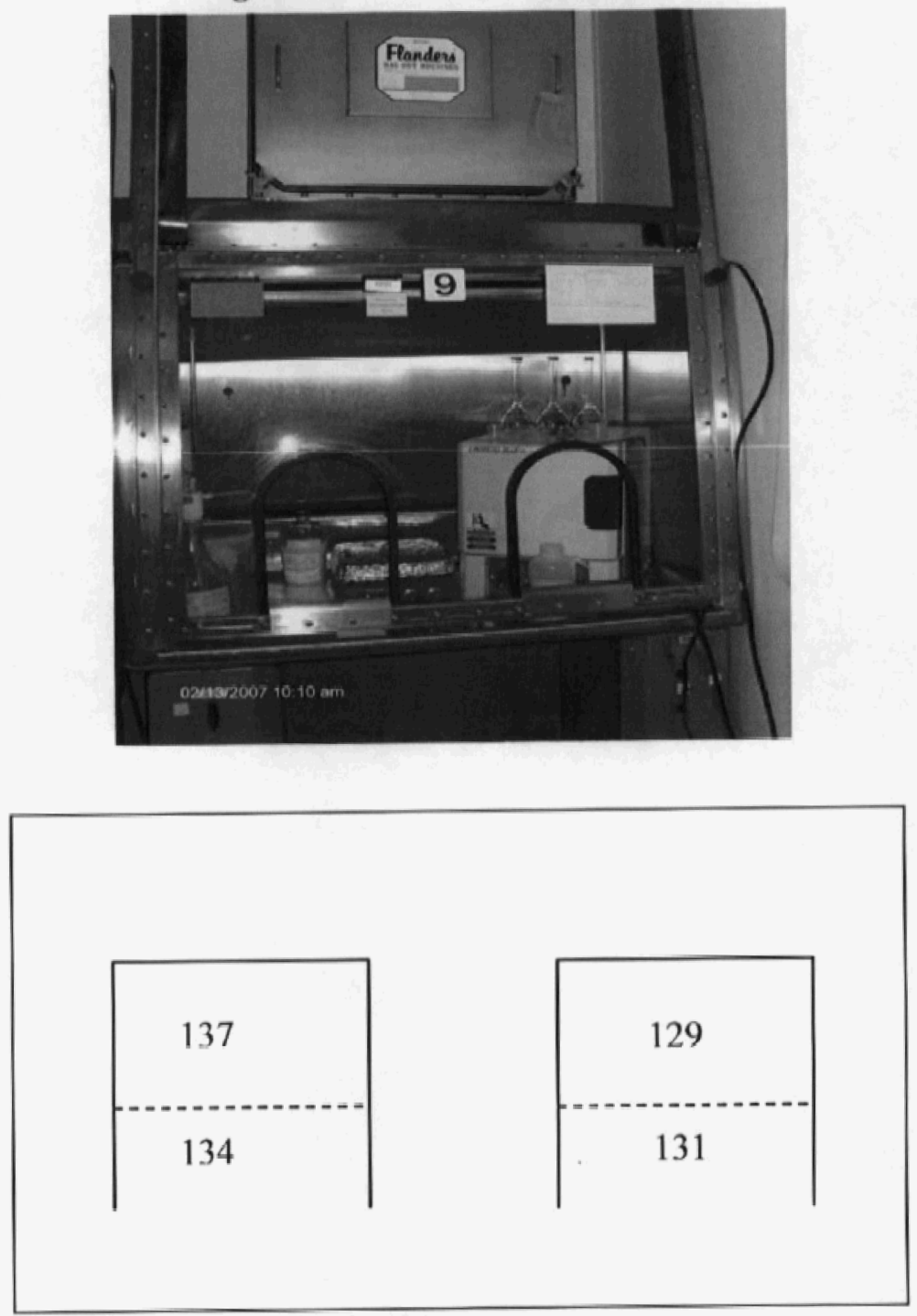

Face Velocity Profile (values are in FPM)

ROOM NO. $\underline{1 B}$

HOOD NO. $\underline{9}$

PERFORMANCE RATING: GOOD 
RPP-RPT-32842, Rev. 0

Figure 16. Room 1GA, Hood 4.
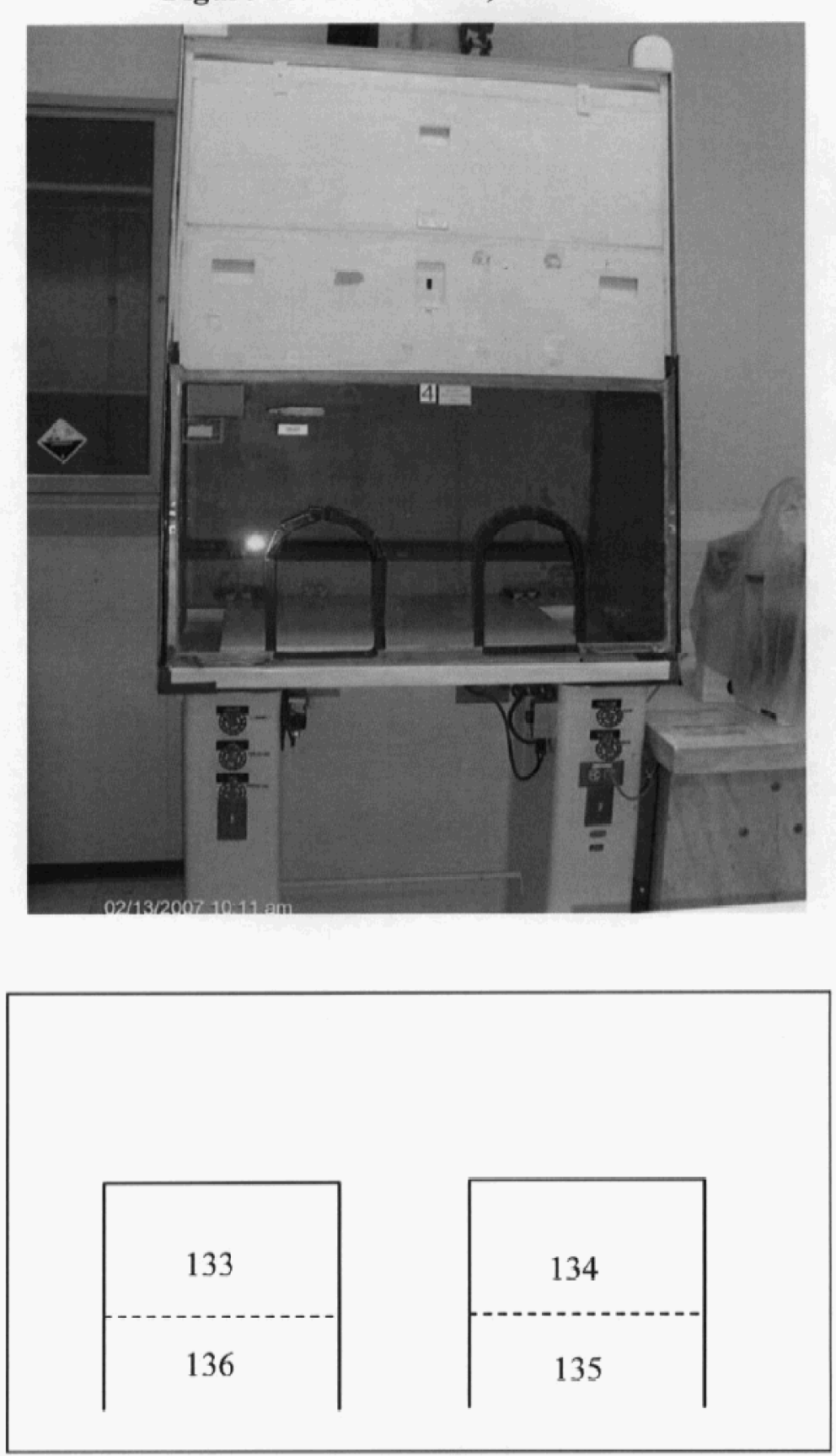

Face Velocity Profile (values are in FPM)

ROOM NO, $\underline{1 \mathrm{GA}}$

HOOD NO. $\quad 4$

PERFORMANCE RATING: GOOD

\author{
Face Velocity Profile (valucs are in FiM)
}

ROOMNO. 
RPP-RPT-32842, Rev. 0

Figure 17. Room 1L, Hood 6.
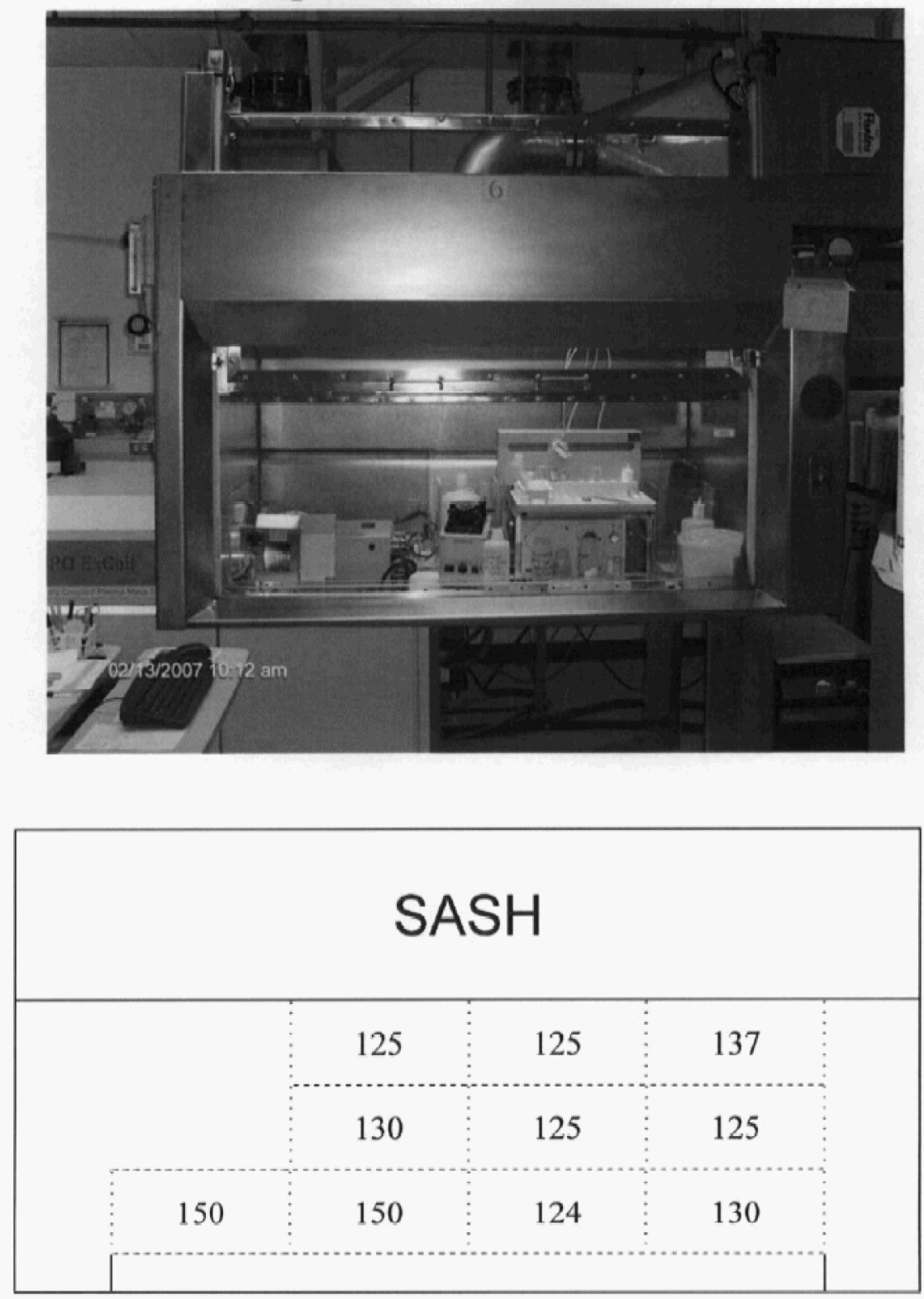

Face Velocity Profile (values are in FPM)

ROOM NO. $\underline{1 \mathrm{~L}}$

HOOD NO. $\underline{6}$

PERFORMANCE RATING: GOOD

Note: PQ ExCell is a product of PQ Energy Services, Inc., Easton, Pennsylvania. 
RPP-RPT-32842, Rev. 0

Figure 18. Room 4H, Hood 12.
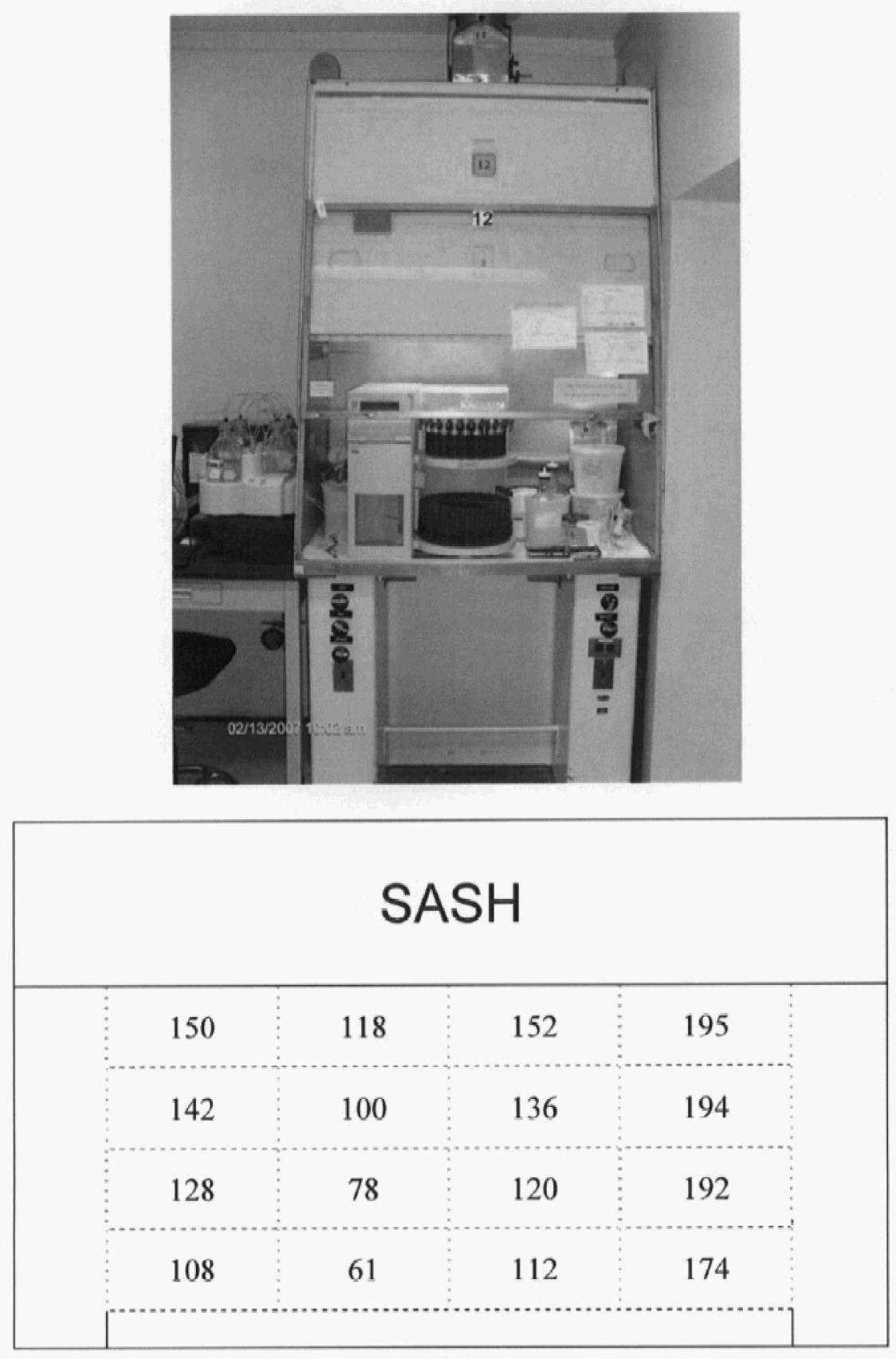

Face Velocity Profile (values are in FPM)

ROOM NO. $\underline{4 \mathrm{H}}$

HOOD NO. $\underline{12}$

PERFORMANCE RATING: GOOD 
RPP-RPT-32842, Rev. 0

Figure 19. Room 4S, Hood 3 .
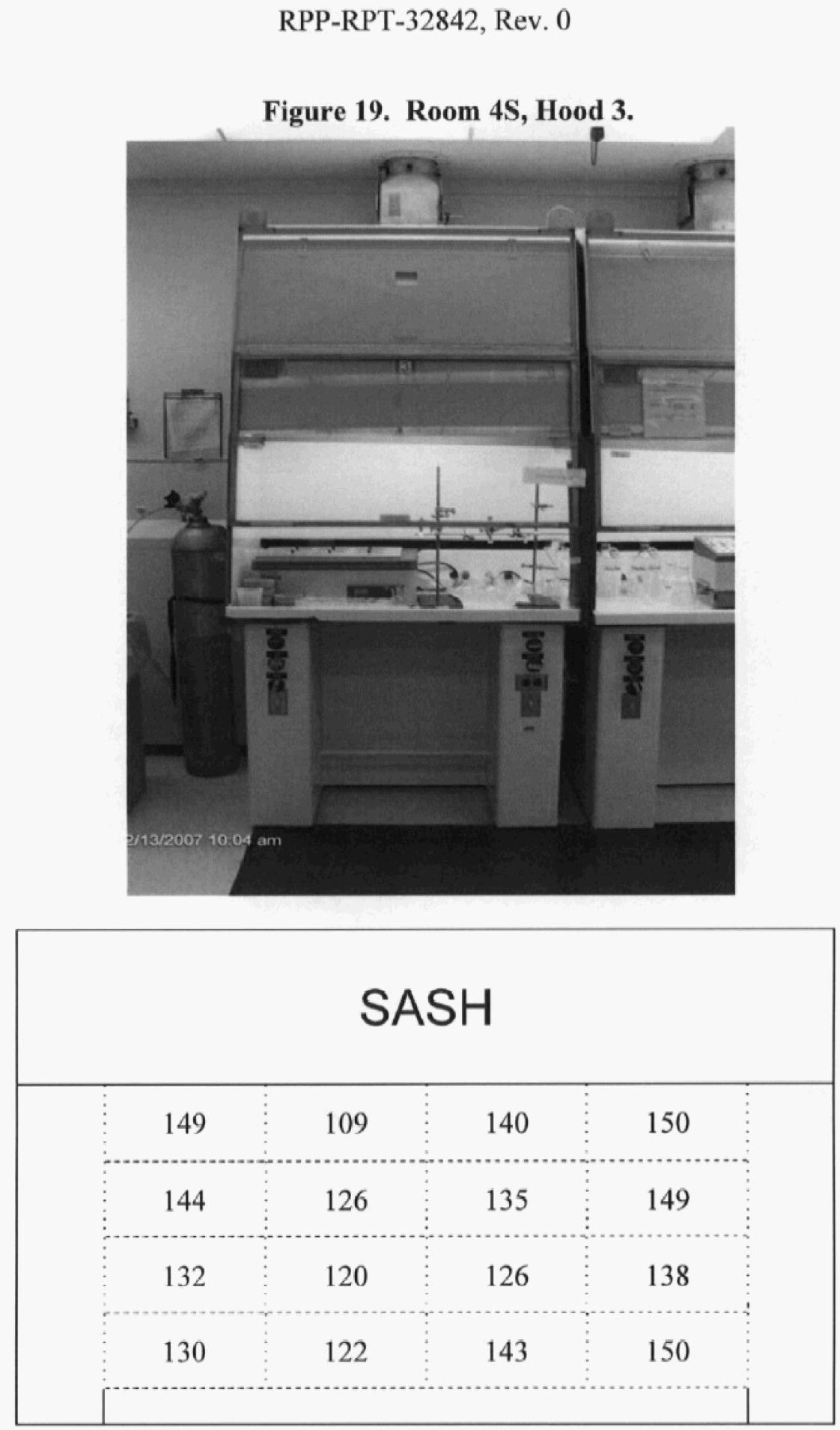

Face Velocity Profile (values are in FPM)

ROOM NO. $\underline{4 \mathrm{~S}}$

HOOD NO. $\underline{3}$

PERFORMANCE RATING: GOOD

\section{SASH}


RPP-RPT-32842, Rev. 0

Figure 20. Room 4S, Hood 4.
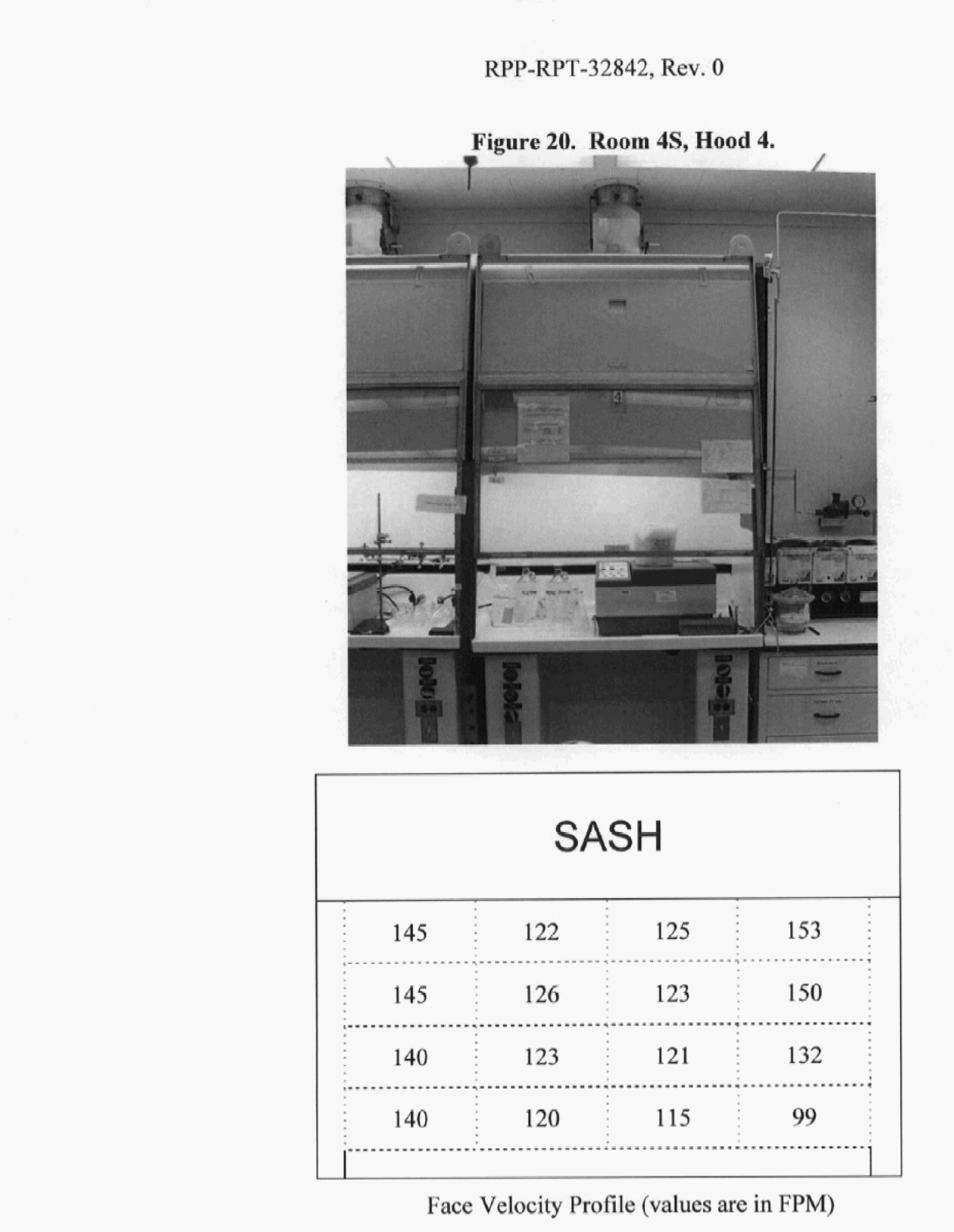

Face Velocity Profile (values are in FPM)

PERFORMANCE RATING: FAIR

\section{Face Velocity Profile (values are in FPM)}

HOODNO. $\underline{4}$

PERFORMANCE RATING: $\underline{\text { FAIR }}$

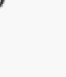

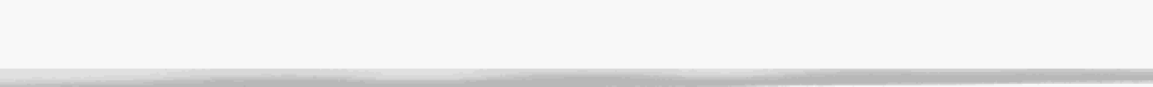

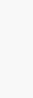

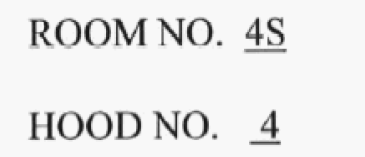

ROOM NO. $\underline{4 \mathrm{~S}}$

HOOD NO. $\underline{4}$

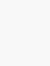

\author{
ROOM NO. $\underline{4 \mathrm{~S}}$
}

(1)

.

(1)

(1)

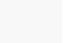


RPP-RPT-32842, Rev. 0

Figure 21. Room 4S, Hood 10.
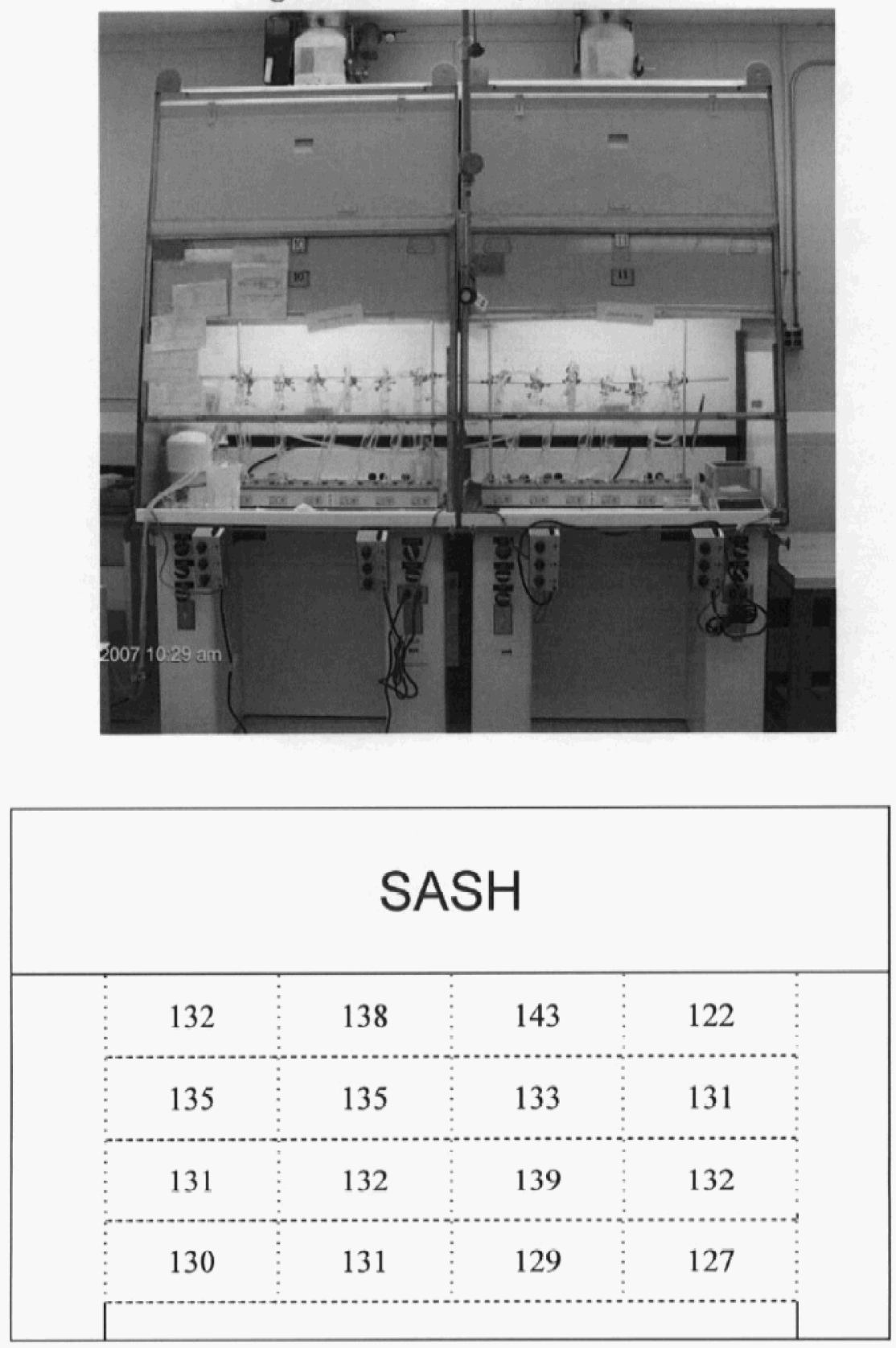

Face Velocity Profile (values are in FPM)

ROOMNO. $\underline{4 \mathrm{~S}}$

HOOD NO. $\underline{10}$

PERFORMANCE RATING： $\underline{\text { GOOD }}$ 
RPP-RPT-32842, Rev. 0

Figure 22. Room 4S, Hood 11.

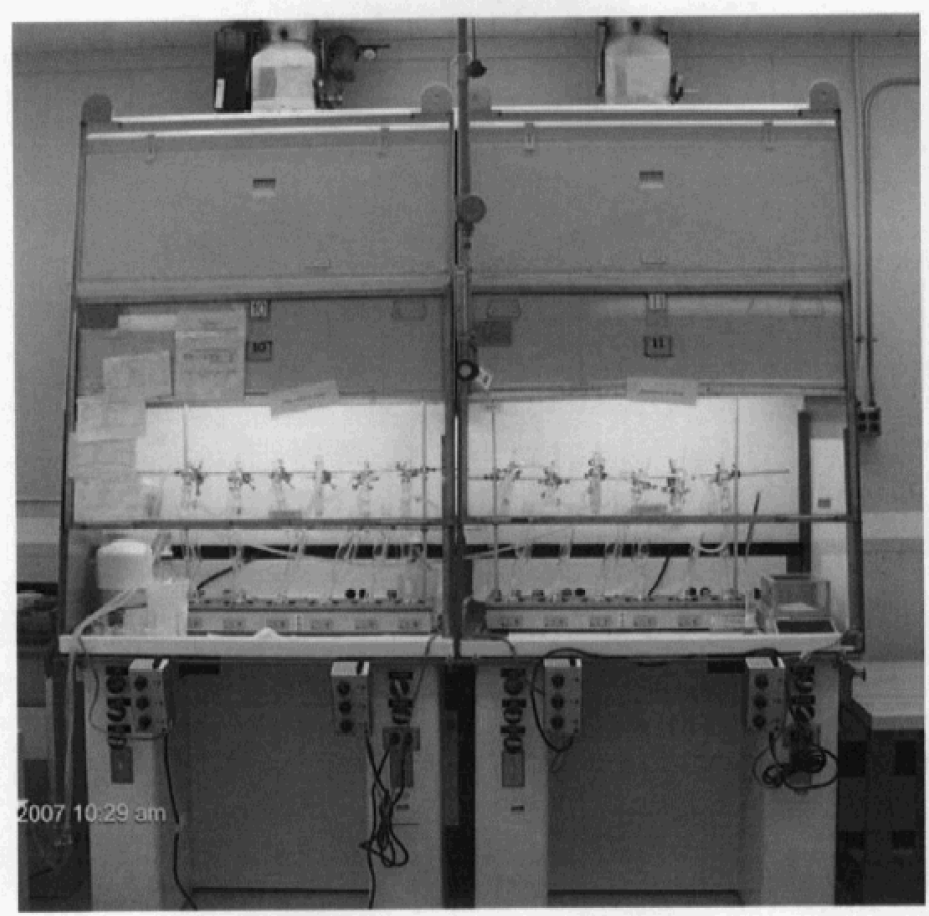

\section{SASH}

\begin{tabular}{|l|c|c|c|c|}
\hline 134 & 132 & 134 & 132 \\
\hline 133 & 129 & 132 & 133 \\
\hline 145 & 131 & 135 & 136 \\
\hline 140 & 133 & 128 & 134 \\
\hline & & 132 & \\
\hline
\end{tabular}

Face Velocity Profile (values are in FPM)

ROOM NO, $\underline{4 \mathrm{~S}}$

HOOD NO. $\underline{11}$

PERFORMANCE RATING: GOOD 
RPP-RPT-32842, Rev. 0

Figure 24. Room 4A, Hood 5.
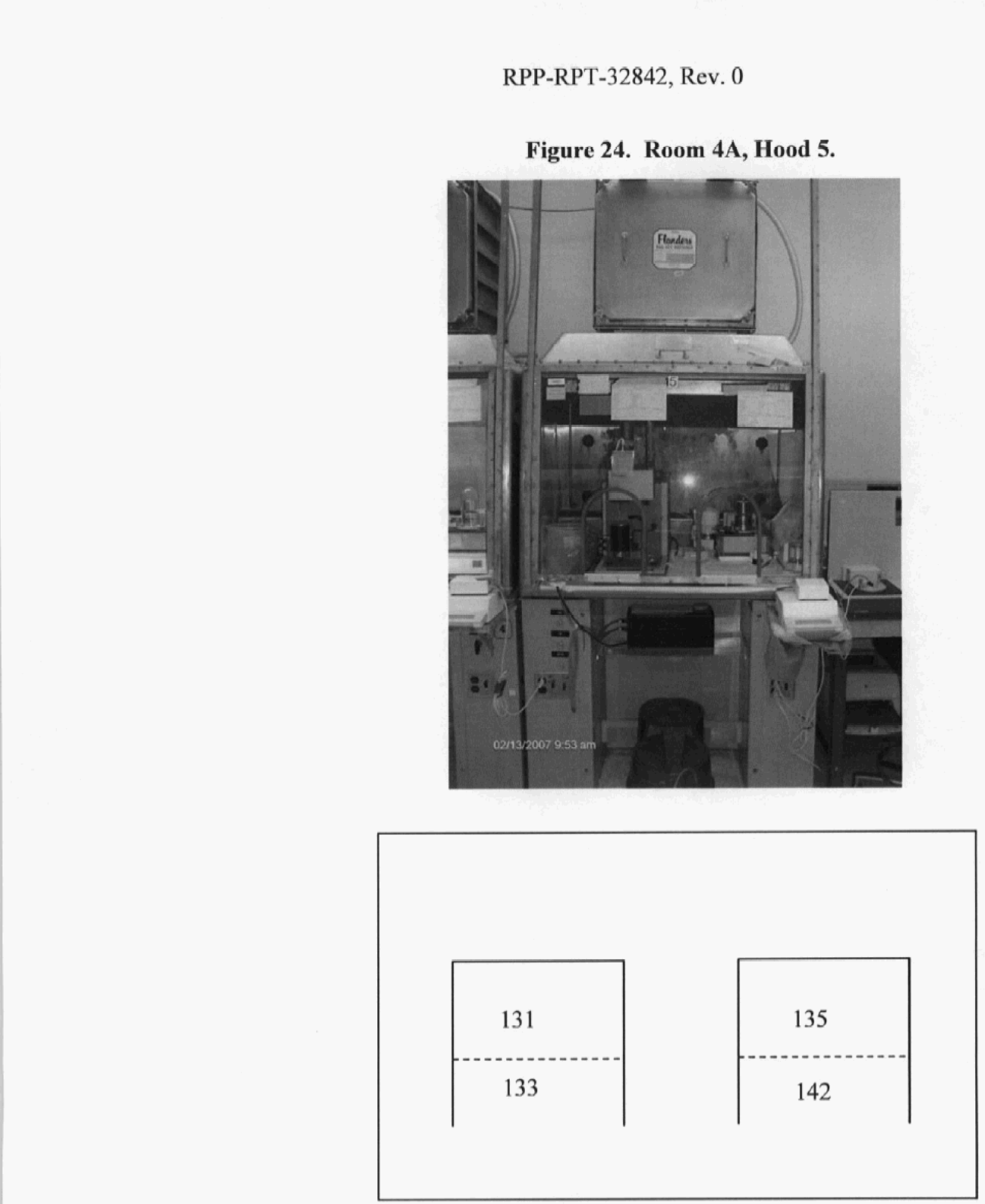

Face Velocity Profile (values are in FPM)

ROOM NO. $\underline{4 \mathrm{~A}}$

HOOD NO. $\underline{5}$

PERFORMANCE RATING: GOOD

\section{Face Velocity Profile (values are in FPM)}


RPP-RPT-32842, Rev. 0

Figure 25. Room 4B, Hood 3 .

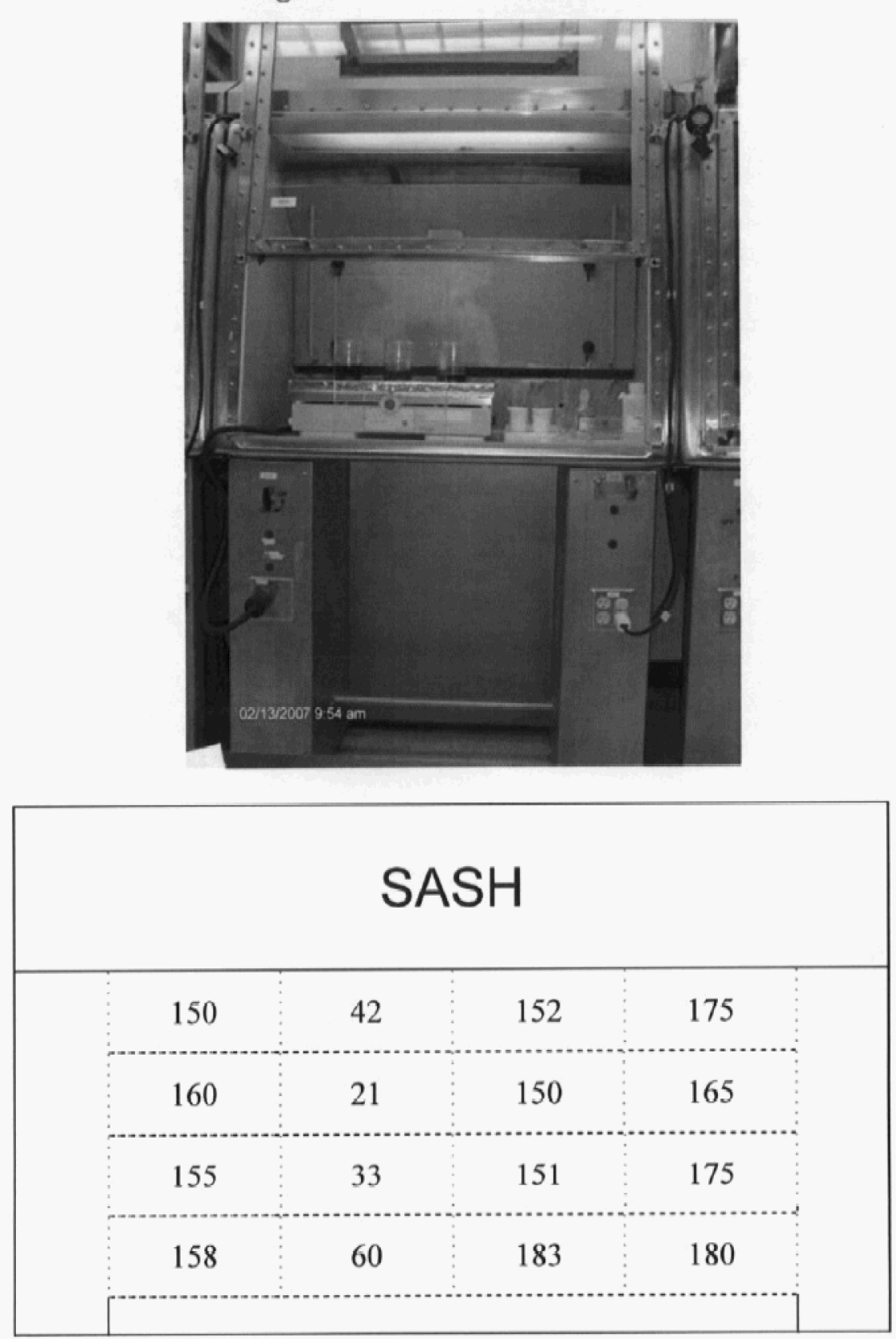

\begin{tabular}{|c|c|c|c|}
\hline 150 & 42 & 152 & 175 \\
\hline 160 & 21 & 150 & 165 \\
\hline 155 & 33 & 151 & 175 \\
\hline 158 & 60 & 183 & 180 \\
\hline
\end{tabular}

Face Velocity Profile (values are in FPM)

ROOM NO. $\underline{4 B}$

HOOD NO. $\underline{3}$

PERFORMANCE RATING: POOR 


$$
\text { RPP-RPT-32842, Rev. } 0
$$

Figure 26. Room 4B, Hood 5.

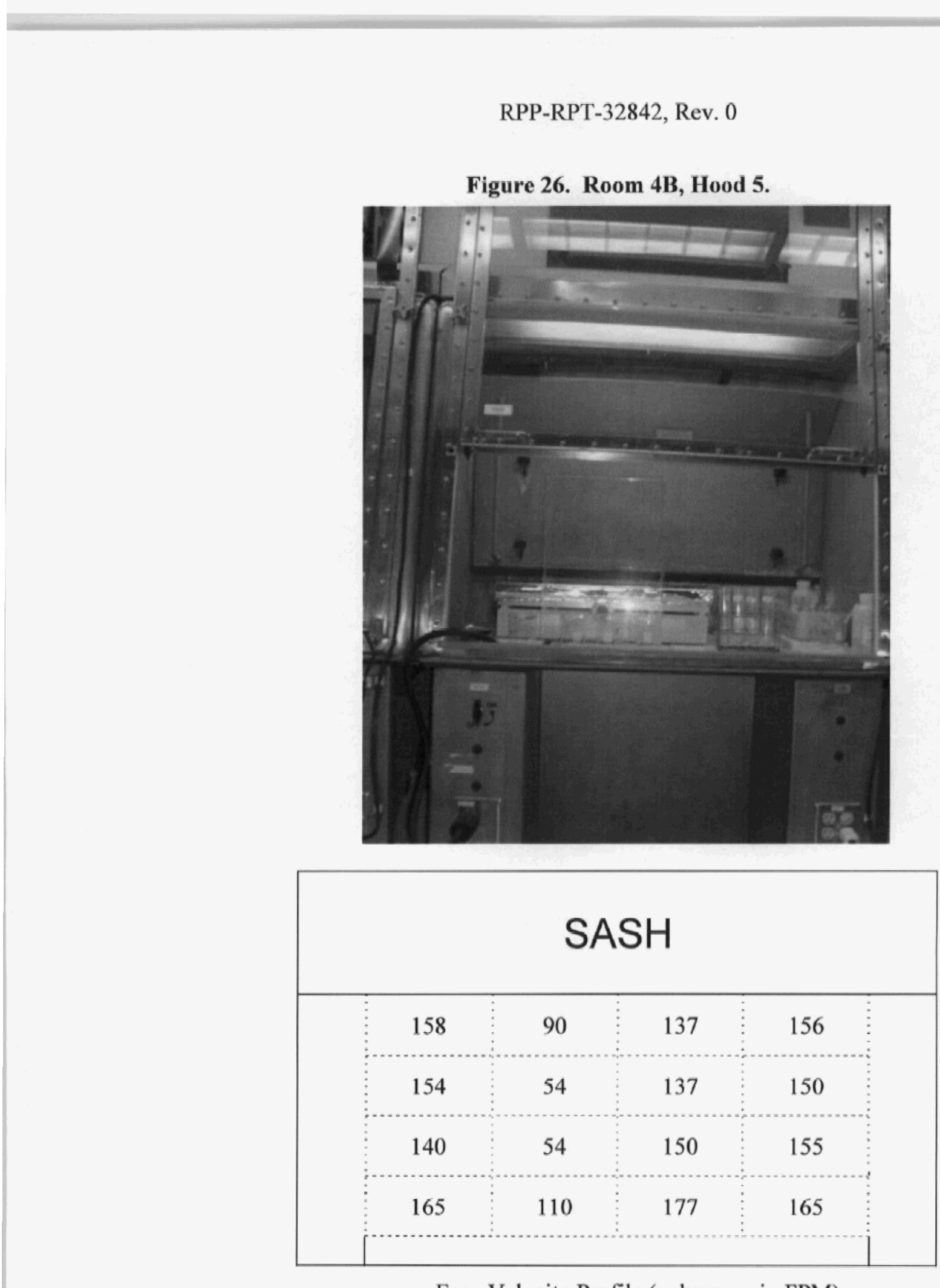

\begin{tabular}{|c|c|c|c|}
\hline 158 & 90 & 137 & 156 \\
\hline 154 & 54 & 137 & 150 \\
\hline 140 & 54 & 150 & 155 \\
\hline 165 & 110 & 177 & 165 \\
\hline
\end{tabular}

Face Velocity Profile (values are in FPM)

\section{Face Velocity Profile (values are in FPM)}
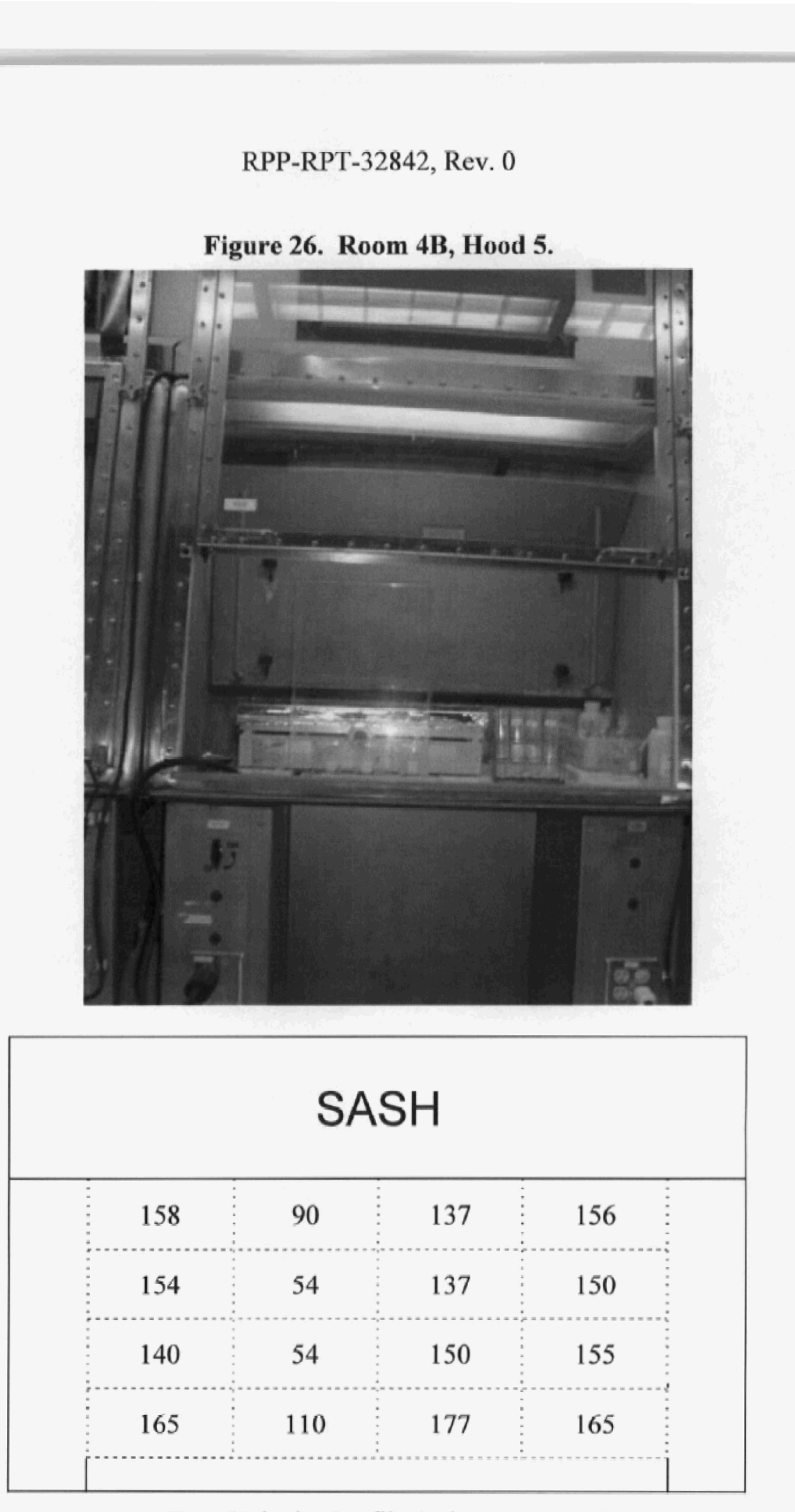

33


RPP-RPT-32842, Rev. 0

Figure 27. Room 4C, Hood 1.
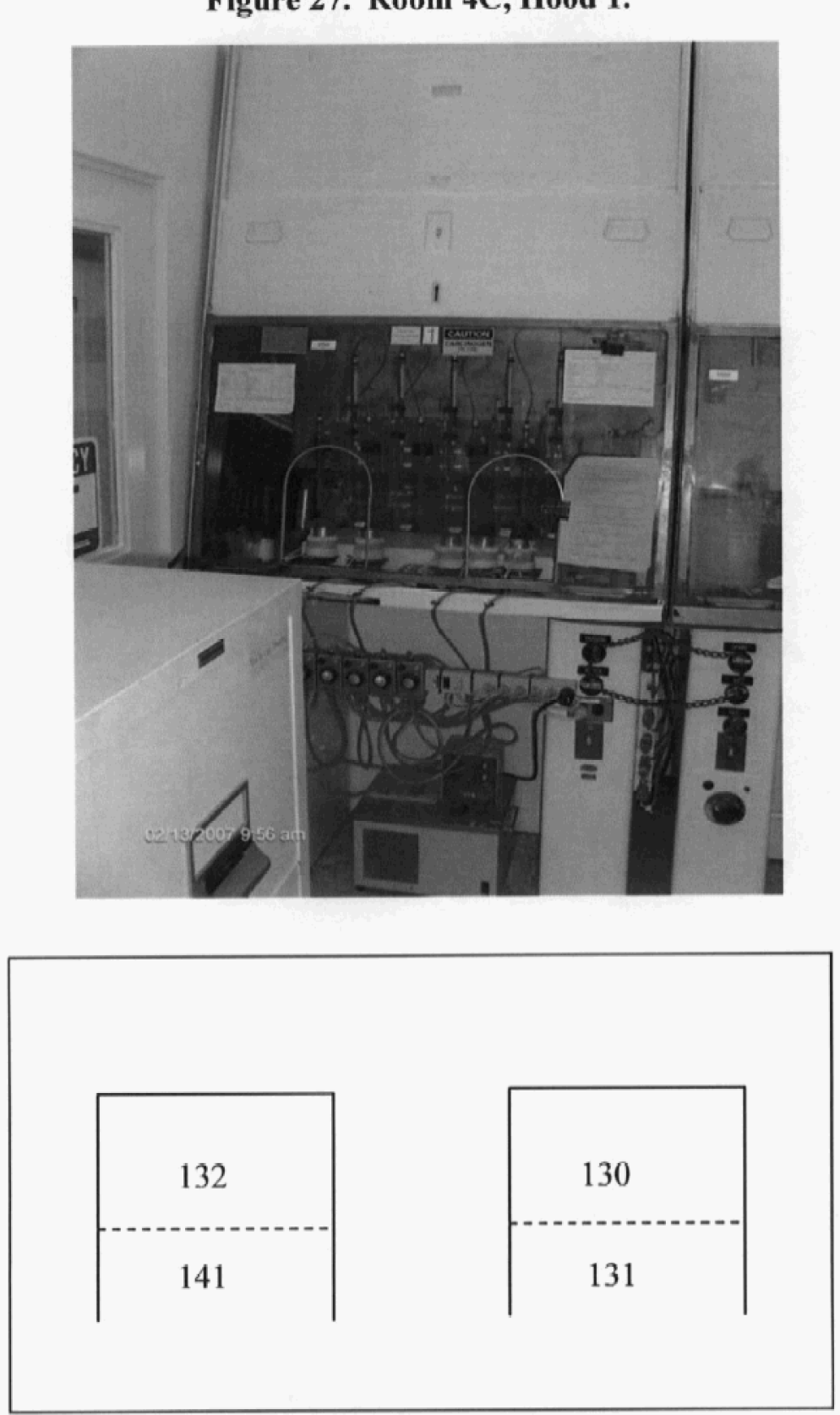

Face Velocity Profile (values are in FPM)

ROOM NO. $\underline{4 \mathrm{C}}$

HOOD NO. 1

PERFORMANCE RATING: GOOD

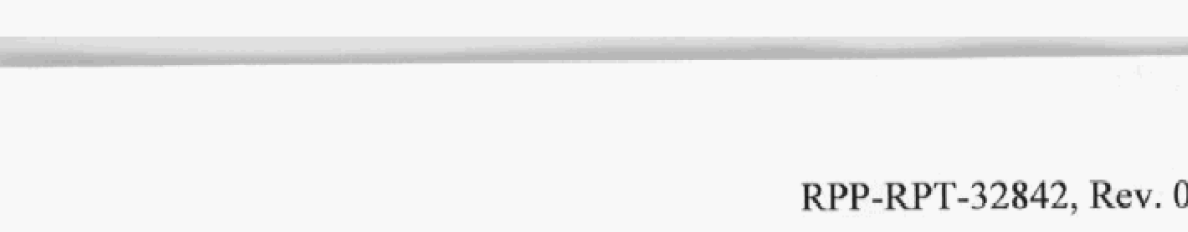

\author{
Face Velocity Profile (values are in FPM)
}


Figure 28. Room 4M, Hood 1.

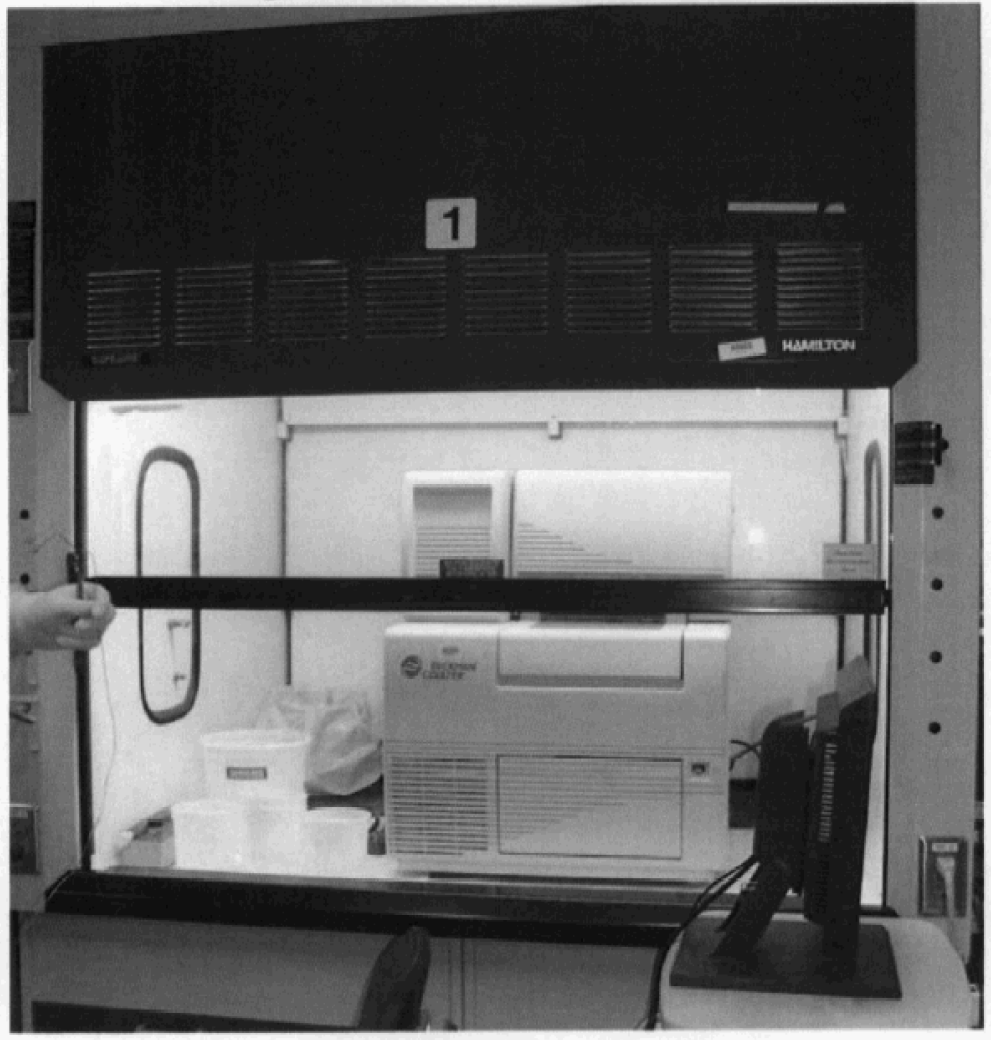

\title{
SASH
}

\begin{tabular}{|c|c|c|c|c|c|}
\hline 164 & 102 & 133 & 155 \\
\hline & 164 & 87 & 130 & 154 \\
\hline 154 & 71 & 135 & 150 \\
\hline & 151 & 70 & 165 & 143 \\
\hline
\end{tabular}

Face Velocity Profile (values are in FPM)

\author{
ROOM NO. $\underline{4 \mathrm{M}}$ \\ HOOD NO. $\quad 1$
}

\section{PERFORMANCE RATING: FAIR}

Note: Safeaire ${ }^{\boxplus a m i l t o n}$ is a product of Hamilton, a part of Thermo Fisher Scientific, Two Rivers, Wisconsin. 
RPP-RPT-32842, Rev, 0

Figure 29. Room 4M, Hood 2.

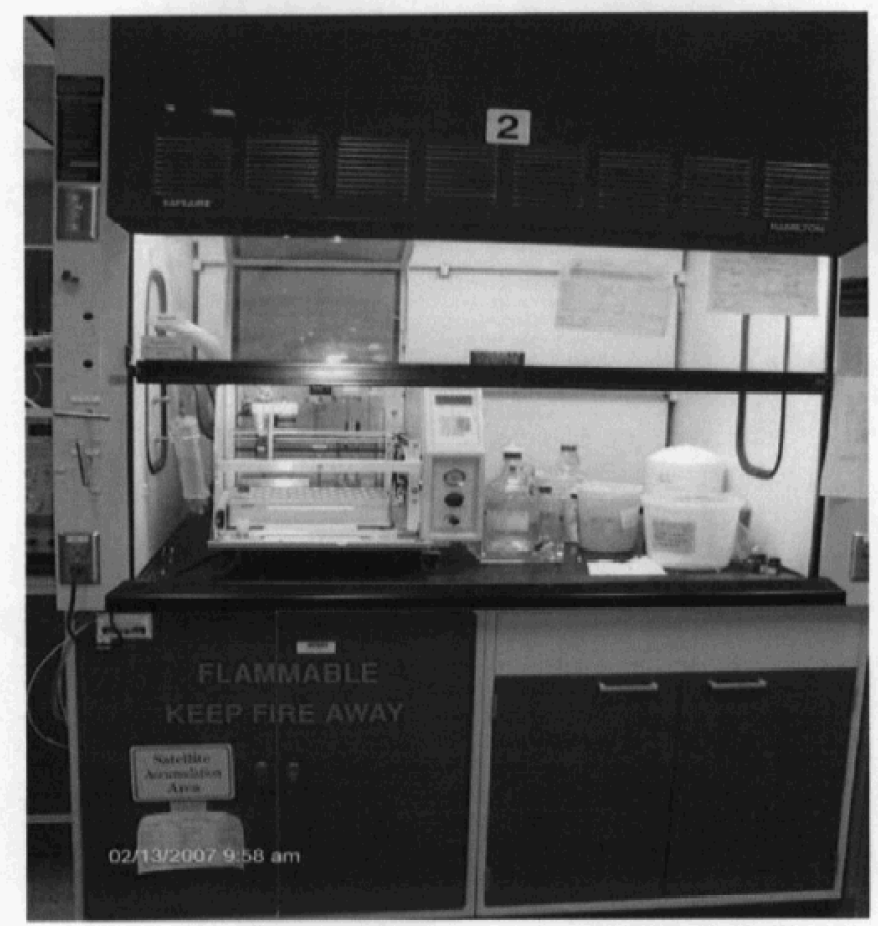

\section{SASH}

\begin{tabular}{|c|c|c|c|}
\hline 150 & 120 & 131 & 142 \\
\hline 136 & 122 & 129 & 135 \\
\hline 133 & 123 & 138 & 136 \\
\hline 141 & 130 & 131 & 140 \\
\hline
\end{tabular}

Face Velocity Profile (values are in FPM)

ROOM NO. $\underline{4 \mathrm{M}}$

HOOD NO. 2

PERFORMANCE RATING: GOOD

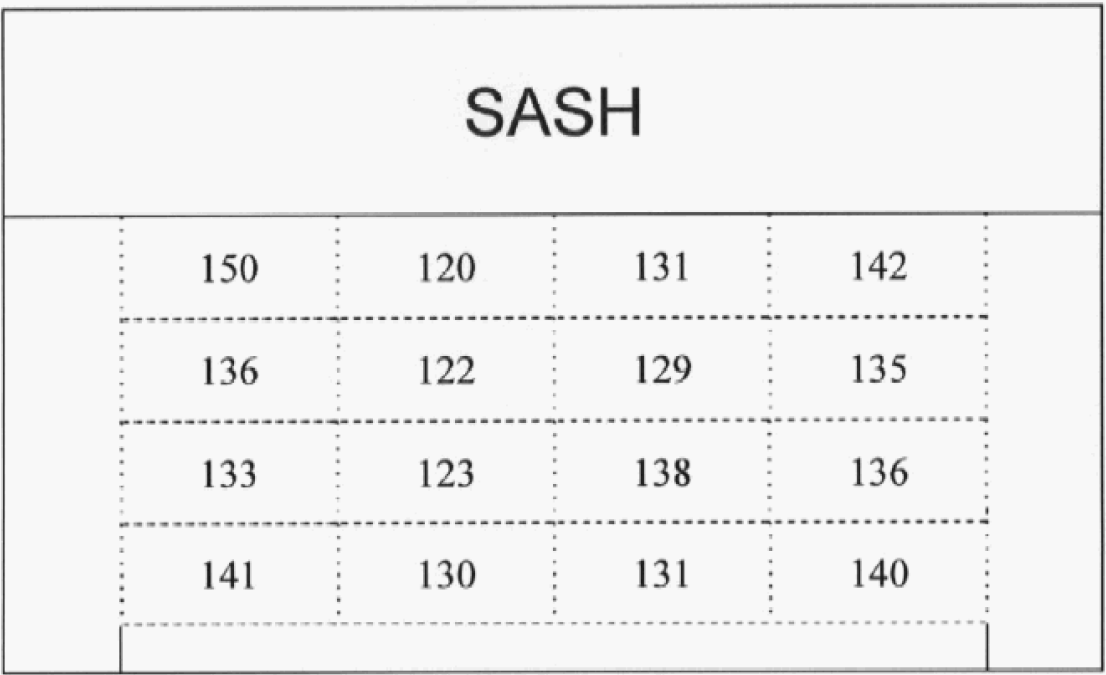

\section{PERFORMANCERATING: GOOP}


RPP-RPT-32842, Rev. 0

Figure 30. Room 4M, Hood 3.

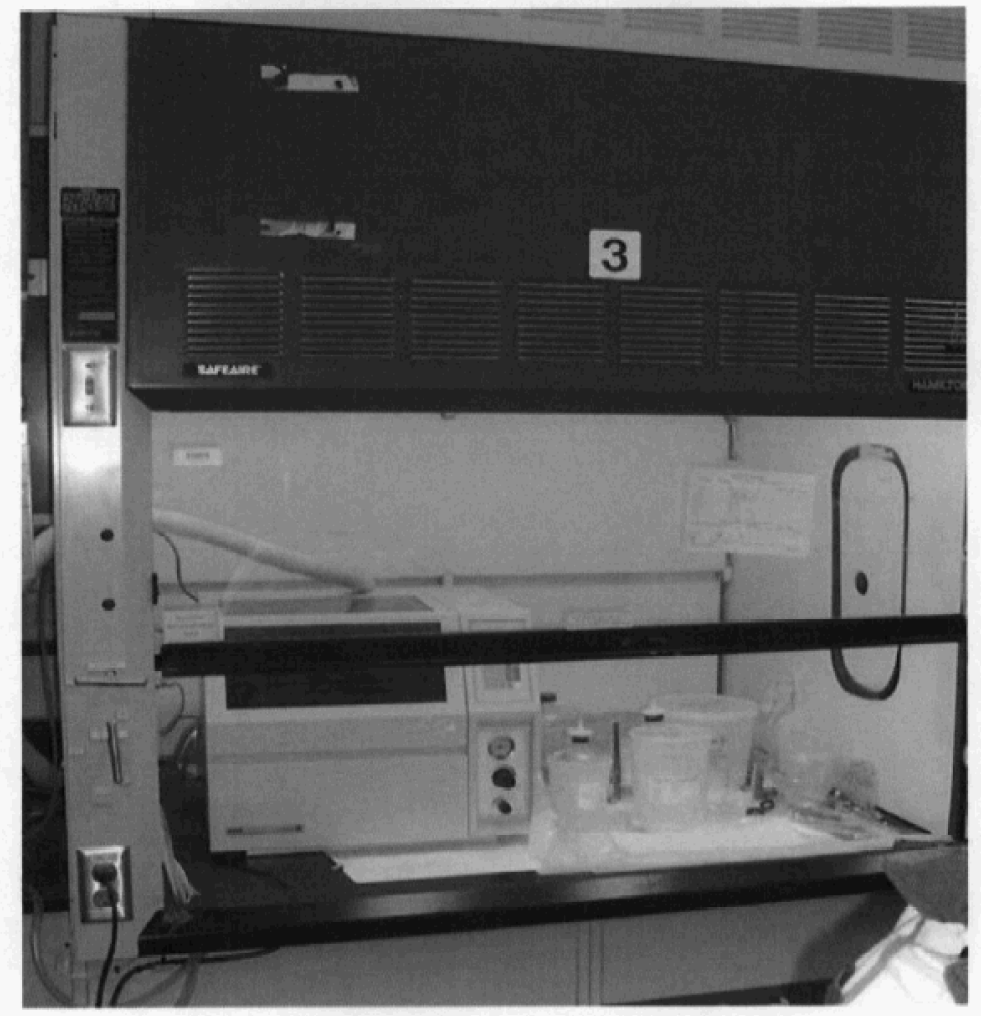

\section{SASH}

\begin{tabular}{|c|c|c|c|}
\hline 133 & 130 & 133 & 143 \\
\hline 128 & 110 & 130 & 146 \\
\hline 125 & 108 & 141 & 145 \\
\hline 125 & 119 & 144 & 147 \\
\hline
\end{tabular}

Face Velocity Profile (values are in FPM)

ROOM NO. $4 \mathrm{M}$

HOOD NO. $\underline{3}$

PERFORMANCE RATING: GOOD

Face Velocity Profile (values are in FPM)

ROOM NO. $\underline{4 \mathrm{M}}$ 
RPP-RPT-32842, Rev. 0

Figure 31. Room 4M, Hood 4.

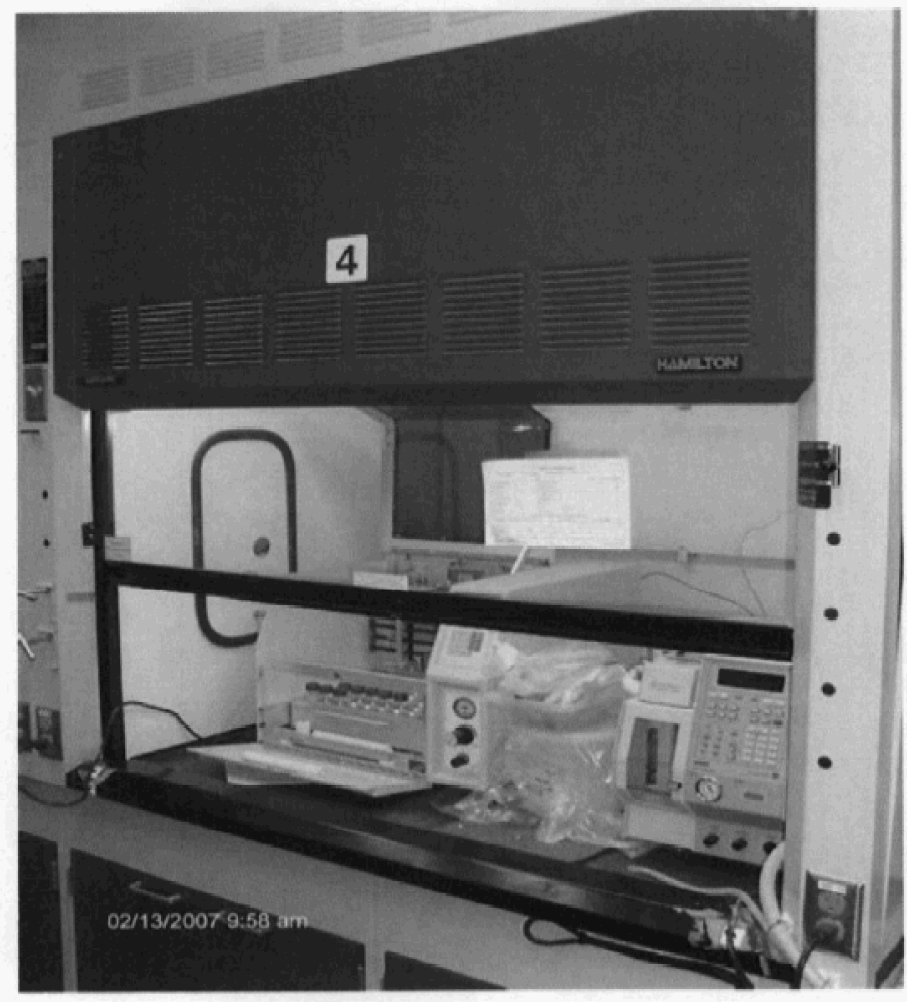

\section{SASH}

\begin{tabular}{|lll|l|l|l|}
\hline$\vdots$ & 144 & 123 & 130 & 141 & $\vdots$ \\
\hline & 162 & 127 & 122 & 127 & $\vdots$ \\
\hline & 145 & 130 & 120 & 115 & $\vdots$ \\
\hline & 142 & 126 & 123 & 110 \\
\hline
\end{tabular}

Face Velocity Profile (values are in FPM)

ROOM NO. $4 \underline{\mathrm{M}}$

HOOD NO. 4

PERFORMANCE RATING： $\underline{\text { FAIR }}$ 
RPP-RPT-32842, Rev. 0

Figure 32. Room 4J, Hood 11.
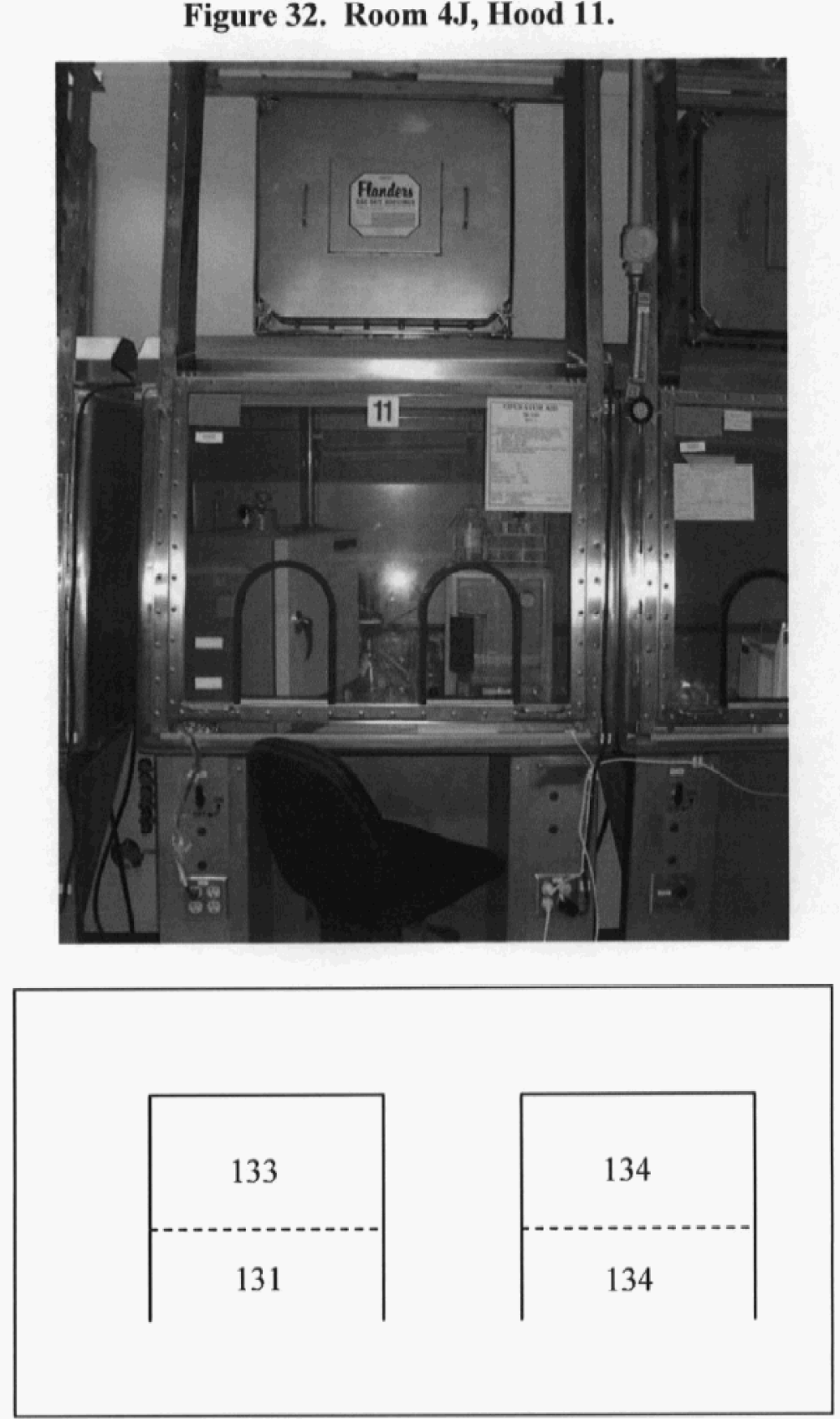

Face Velocity Profile (values are in FPM)

ROOM NO. $\underline{4 \mathrm{~J}}$

HOOD NO. 11

PERFORMANCE RATING: FAIR

\section{Face Velocity Profile (values are in}


RPP-RPT-32842, Rev. 0

Figure 33. Room 2H, Hood 1.
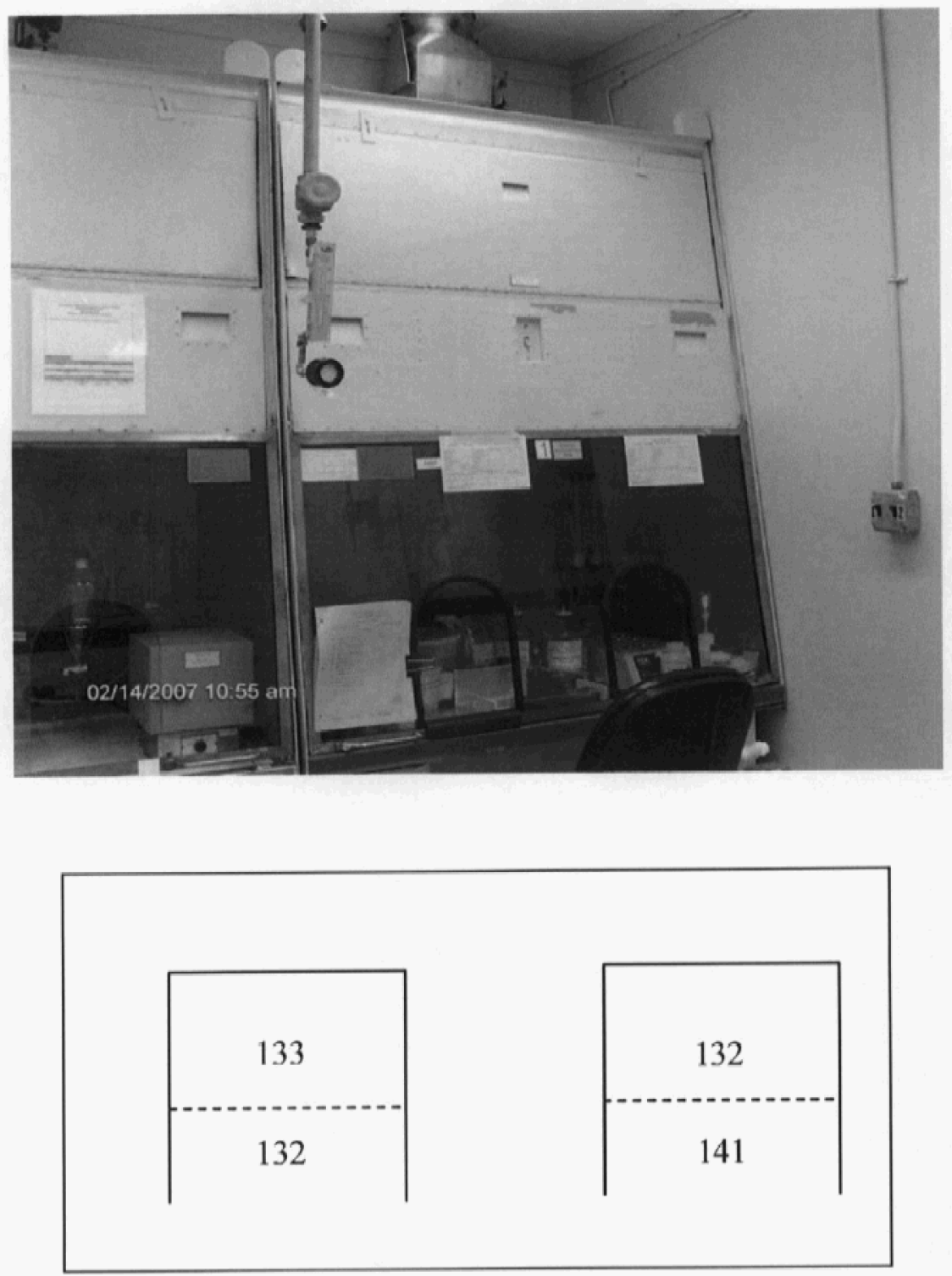

Face Velocity Profile (values are in FPM)

ROOM NO. $2 \mathrm{H}$

HOOD NO. 1

PERFORMANCE RATING： FAIR 
RPP-RPT-32842, Rev. 0

Figure 34. Room 2B, Hood 3.
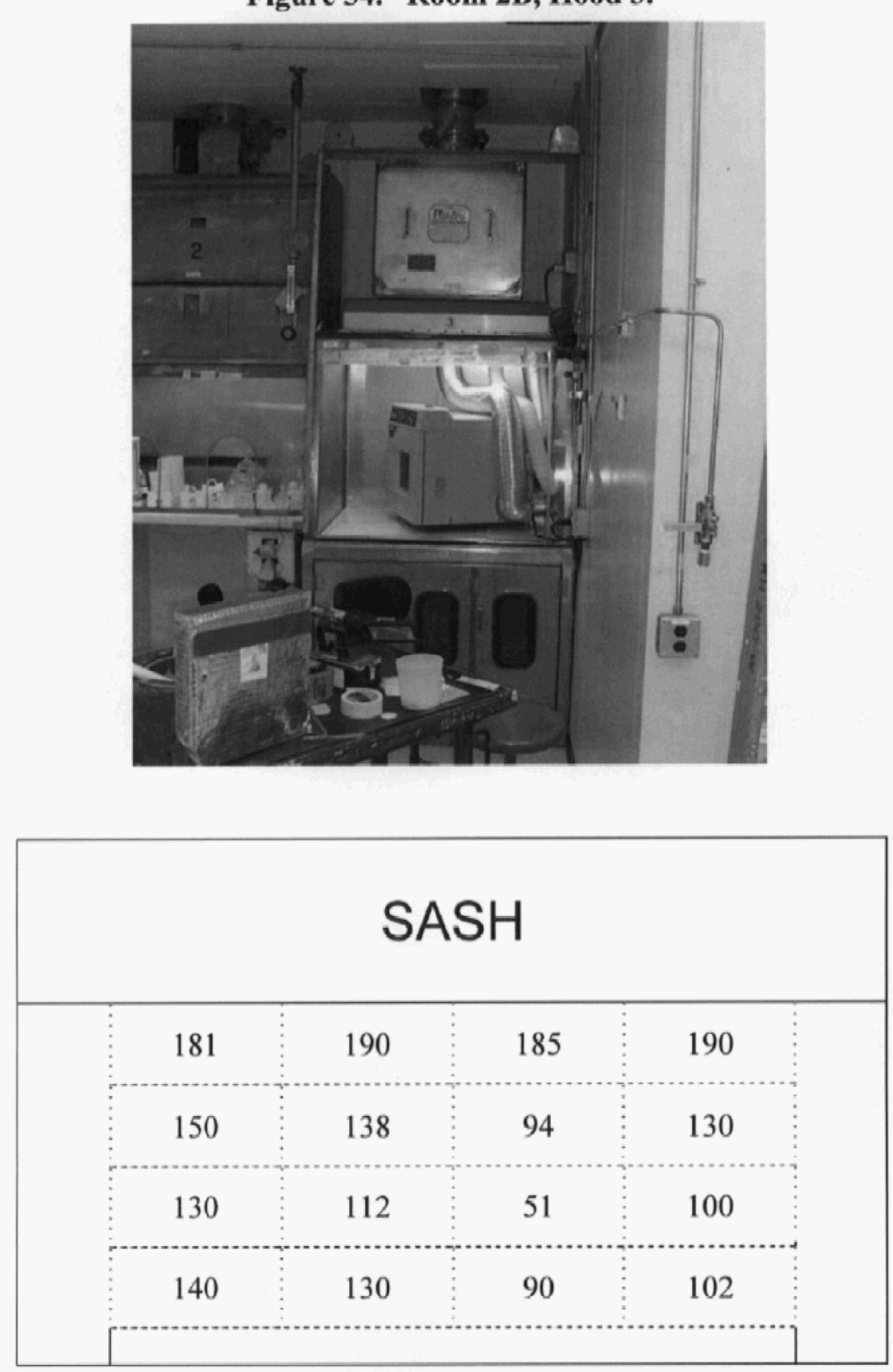

Face Velocity Profile (values are in FPM)

ROOM NO. $\underline{2 B}$

HOOD NO. $\underline{3}$

PERFORMANCE RATING: GOOD

SASH

\section{Face Velocity Profile (values are in FPM)}

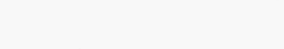


Figure 35. Room 4B, Hood 3 (RETEST).

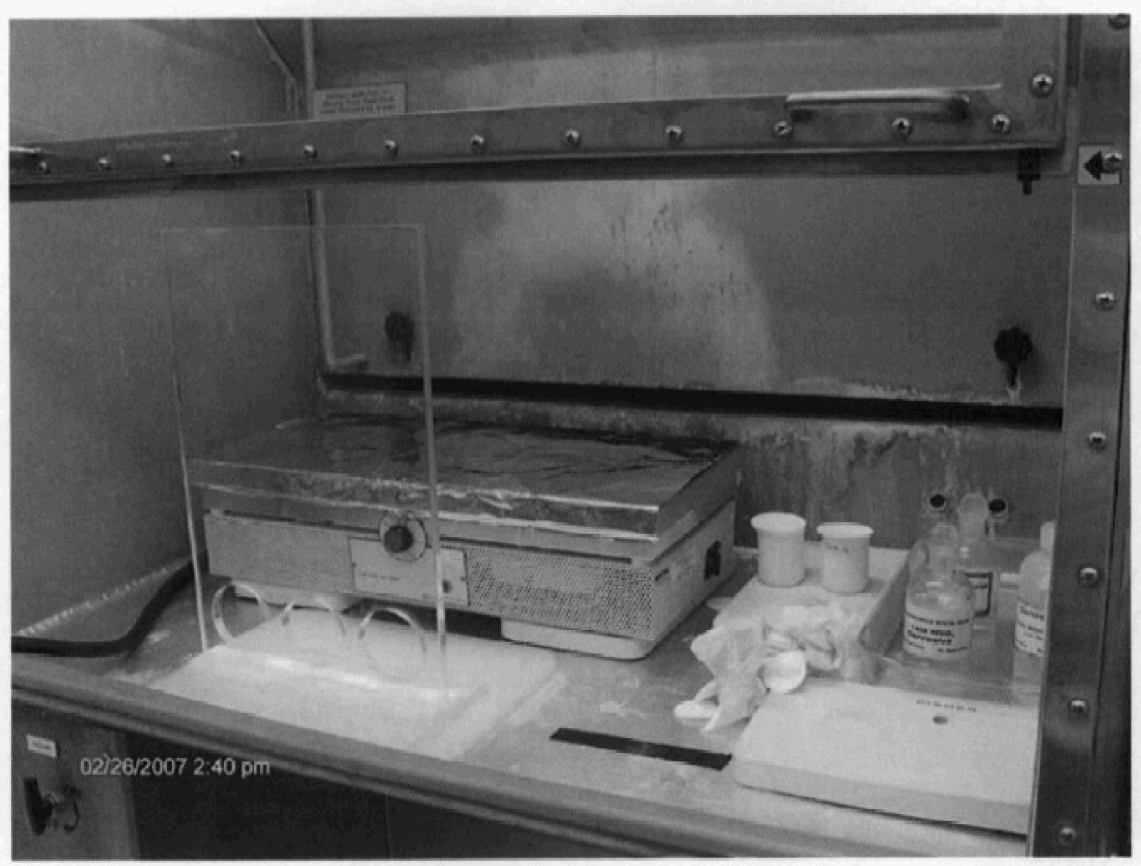

\begin{tabular}{|c|c|c|c|}
\hline 151 & 55 & 138 & 170 \\
\hline 143 & 53 & 140 & 167 \\
\hline 141 & 32 & 138 & 172 \\
\hline 163 & 115 & 180 & 183 \\
\hline
\end{tabular}

Face Velocity Profile (values are in FPM)

ROOM NO. $\underline{4 B}$

HOOD NO. $\underline{3}$

PERFORMANCE RATING： FAIR 
RPP-RPT-32842, Rev. 0

Figure 36. Room 4B, Hood 5 (RETEST).

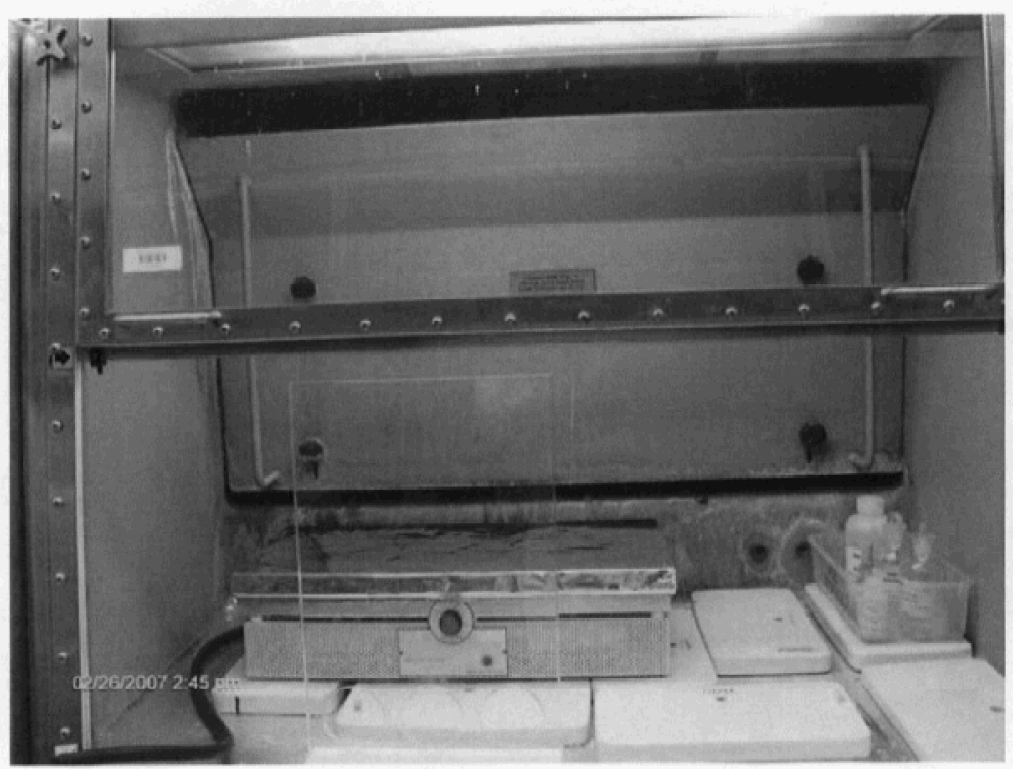

\begin{tabular}{|c|c|c|c|}
\hline \multicolumn{5}{|c|}{ HORIZONTAL } \\
SASH \\
\hline 149 & 60 & 130 & 153 \\
\hline 134 & 52 & 135 & 154 \\
\hline 142 & 75 & 111 & 144 \\
\hline 150 & 96 & 169 & 190 \\
\hline
\end{tabular}

Face Velocity Profile (values are in FPM)

ROOM NO. 4 $\underline{\text { B }}$

HOOD NO. $\underline{5}$

PERFORMANCE RATING: FAIR

\begin{abstract}
HOOD
\end{abstract}


RPP-RPT-32842, Rev. 0

Figure 37. Room 1K Hood 2 (RETEST).

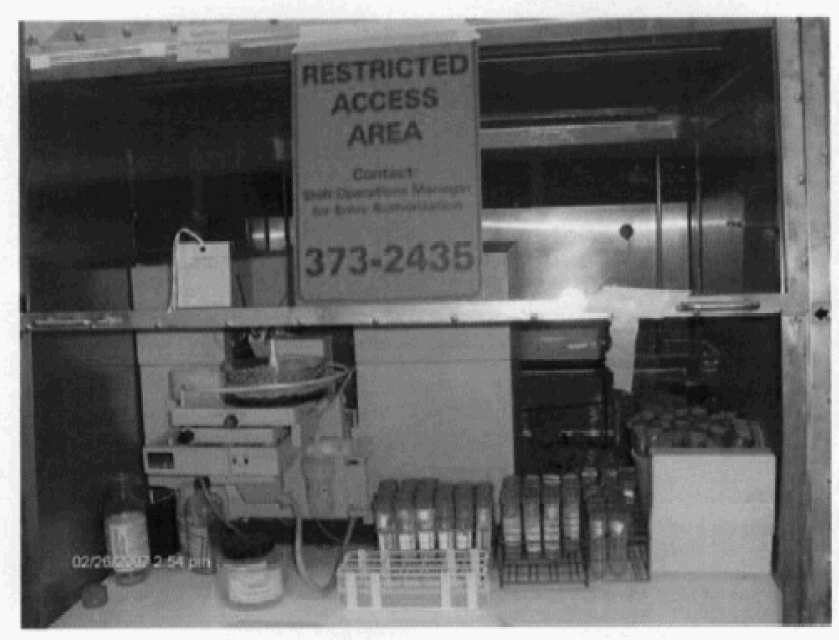

\begin{tabular}{|c|c|c|c|}
\hline 143 & 140 & 134 & 148 \\
\hline 134 & 134 & 141 & 143 \\
\hline 135 & 131 & 134 & 139 \\
\hline 140 & 135 & 142 & 133 \\
\hline
\end{tabular}

Face Velocity Profile (values are in FPM)

ROOM NO. $\underline{1 \mathrm{~K}}$

HOOD NO. 2

PERFORMANCE RATING: FAIR 
Figure 38. Room 1K, Hood 4 (RETEST).

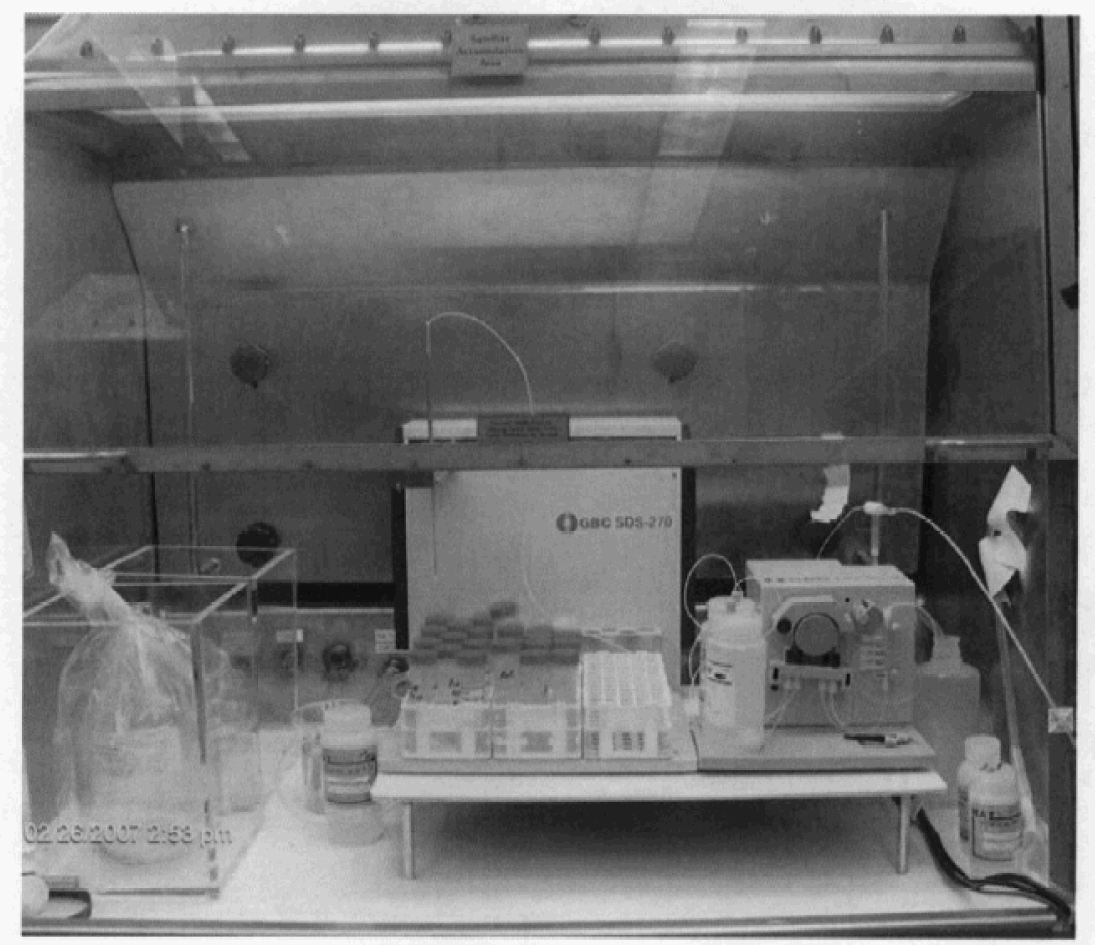

\begin{tabular}{|c|c|c|c|}
\hline 151 & 133 & 137 & 13 \\
\hline 130 & 129 & 130 & 136 \\
\hline 121 & 132 & 138 & 146 \\
\hline 123 & 131 & 139 & 145 \\
\hline
\end{tabular}

Face Velocity Profile (values are in FPM)

ROOM NO. $\underline{1 \mathrm{~K}}$

HOOD NO, $\quad 4$

\section{PERFORMANCE RATING: POOR}

Note: GBC SDS-270 is a product of GBC Scientific Equipment, Dandenong, Victoria, Australia. 


\section{APPENDIX: \\ LABORATORY FUME HOOD PERFORMANCE TESTING PLAN}

\section{Introduction}

Selected fume hoods within the 222-S Laboratory will be tested to ensure acceptable containment exists in their "as-used" state. Based on the test results, an engineering evaluation will be performed. This evaluation will establish initial performance ratings for the hoods tested. Recommendations will be made to improve fume hood performance ratings through operator work practices, equipment placement, and reduction in sash height.

The selected testing methods are adopted from the ANSI/ASHRAE 110-1995, Method of Testing Performance of Laboratory Fume Hoods. The methods used will provide for a qualitative and quantitative evaluation of hood performance. The testing methods and their associated steps described in this plan may be completed in any order.

\section{General Test Conditions}

1. Fume hoods sashes will be in the normal operating position.

2. Testing shall be conducted with normal hood apparatus in place.

3. Entry doors to the rooms containing fume hoods to be tested will be in their normal configuration (in most cases open).

\section{Preliminary Data}

1. A sketch or drawing of each room shall be provided to indicate test hood location, other hoods, the location of significant equipment nearby, and door configurations.

2. The fume hood type, size, and sash configuration shall be noted.

3. The location of material storage and amount of work surface space occupied by materials and/or equipment within the fume hood shall be noted.

\section{$\underline{\text { Flow Visualization Test }}$}

The purpose of this test is to visualize the capacity of a fume hood to contain vapors and render an observation of hood performance as it is typically used. In the following tests, it is expected that all vapors shall be carried to the rear of the fume hood and exhausted. Any movement of vapor towards the face of the fume hood will be defined as negative characteristic airflow, and any lack of movement will be defined as dead air space. Any vapor escaping the fume hood face during any of the tests will result in a "FAILURE" rating for the fume hood. 
Testing will be conducted as follows:

1. General Visualization Test -

Using a container of dry ice and water, conduct a complete traverse of the fume hood face to determine that a positive flow of air into the hood is being maintained over the entire fume hood face. No reverse flow should be evident (however, some initial turbulence at the vapor challenge receptacle is acceptable).

2. Local Visualization Test-

a. Using a container of dry ice and water, challenge vapor test along each side and across the working surface of the fume hood, in a line parallel to the fume hood face and 6 in. back into the fume hood. Note airflow patterns.

b. Move the challenge media to the rear of the fume hood. Note airflow patterns and clearing time.

c. Move the challenge media to the upper portion of the fume hood. Note airflow patterns and clearing time.

d. Move the challenge media around any equipment/material in the fume hood. Note airflow patterns and clearing time.

3. Large Volume Visualization Test-

Place a container of dry ice and water in the center of the fume hood sash opening on the work surface 6 in. back from the rear edge of the sash. Note airflow patterns. No reverse flow of vapor should be evident into the work area.

\section{Face Velocity Measurements}

The purpose of this test is to quantitatively measure air velocity at the fume hood face.

Measurement locations will be established at the hood face in accordance with Analytical Technical Services Maintenance Procedure 2S99003, "Open Face/Arm Port Hood Airflow Test, 222-S."

Air velocity measurements will be taken using a thermal anemometer. Flow rates in feet per minute (FPM) will be obtained at established locations and recorded.

An average face velocity of 125 to 140 FPM shall be established for each hood. 


\section{Performance Classifications}

Following review of the testing data, performance ratings will be established for each fume hood tested. The ratings and criteria are as follows:

\section{Good}

Challenge vapors are adequately captured at the face of the fume hood and are drawn into the fume hood and exhausted. Quick clearance times are observed. Limited fume hood roll vortex. No visible escape of vapors during any testing phase. Turbulence and eddying will be observed in arm ported fume hoods between arm port openings.

\section{Fair}

Some challenge vapors reverse flow and migrate toward the fume hood face but are recaptured and exhausted, or dead air spaces are present that would result in a slow migration of vapors toward the fume hood face but are again recaptured and exhausted. Limited turbulent vortex is observed. No visible escape of vapors during any testing phase.

\section{Poor}

Challenge vapors reverse flow near fume hood face. Dead air spaces are present that result in slow migration of vapors toward the fume hood face. Slow capture and clearance of challenge vapors. There is an observed potential for escape of vapors from the fume hood.

\section{Failure}

Challenge vapors migrate directly to the fume hood face and escape from the interior of the hood into the surrounding area.

\section{Discussion}

Regardless of fume hood performance rating, consideration must be made with regard to the toxicological properties of the materials being handled or anticipated to be handled within any fume hood. A facility safety representative should be contacted to evaluate fume hood conditions and proposed operations.

It is strongly recommended that any fume hood that fails flow visualization testing be temporarily removed from service. Additional testing should be conducted as soon as possible to identify the source(s) affecting performance. Once corrective actions have been completed, fume hood performance testing should be repeated to validate any rating change. 